\title{
RESERVOIR QUALITY OF 84 TERTIARY SANDSTONES FROM THREE EXPLORATORY WELLS, BRISTOL BAY BASIN, ALASKA PENINSULA
}

\author{
by
}

Kenneth P. Helmold ${ }^{1}$, Donald W. Brizzolara ${ }^{1}$, and Rocky R. Reifenstuhl ${ }^{2}$

\section{INTRODUCTION}

The State of Alaska began holding areawide oil and gas lease sales for the Alaska Peninsula on October 26, 2005 (fig. 1). The Department of Natural Resources (DNR) has instituted several studies aimed at providing data necessary for the resource evaluation. This report documents one of these studies undertaken by DOG to determine the quality of potential Tertiary sandstone reservoirs.

Eighty-four thin sections of siltstone and sandstone were examined from three exploratory wells: Arco North Aleutian COST \#1 (30 km [18.6 mi] offshore), Amoco Becharof State \#1, and General Petroleum Great
Basins \#1, on the Alaska Peninsula (fig. 1). The wells were chosen for study because conventional cores or conventional core chips were readily accessible. Wells with only cuttings were excluded from study but may be examined in future efforts. The North Aleutian COST \#1 well was sampled at the ConocoPhillips Bayview core facility in Anchorage, Alaska, by Division of Geological \& Geophysical Surveys (DGGS) personnel. The Becharof State \#1 and Great Basins \#1 wells were sampled at the Alaska Geologic Materials Center (GMC) in Eagle River, Alaska. Where possible (Becharof State \#1 and North Aleutian COST \#1), 2.5-cm- (1-inch-) diameter

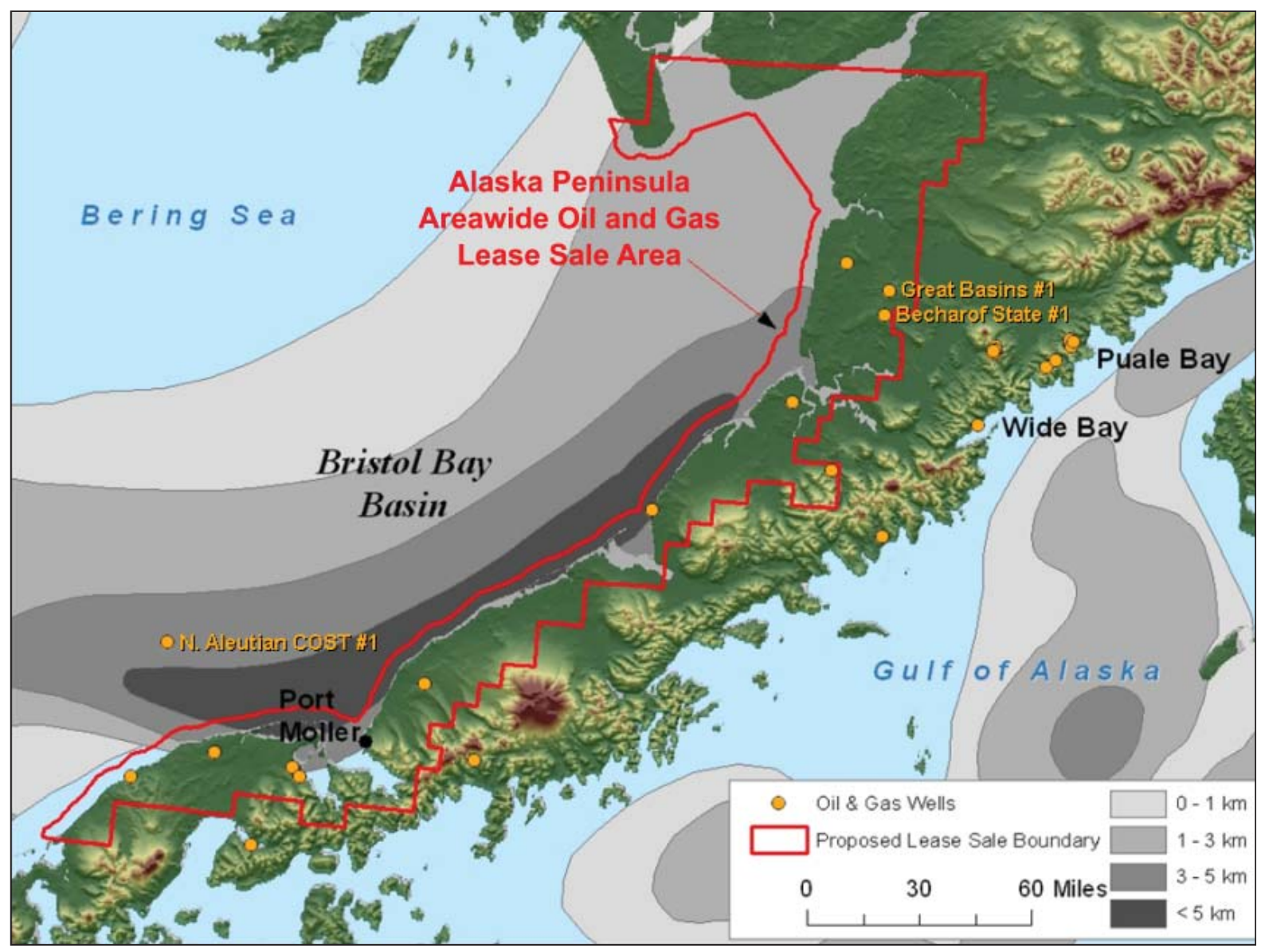

Figure 1. Shaded relief map of the Alaska Peninsula showing the lease sale area and location of oil and gas wells.

${ }^{1}$ Alaska Division of Oil \& Gas, 550 W. 7th Ave., Suite 800, Anchorage, Alaska 99501

${ }^{2}$ Alaska Division of Geological \& Geophysical Surveys, 3354 College Rd., Fairbanks, Alaska 99709-3707 
plugs were drilled from the conventional cores to obtain thin sections and porosity-permeability $(\varphi-\mathrm{k})$ measurements from the same sample. Only small core chips were available for the Great Basins \#1 well, so no $\varphi-k$ measurements could be obtained. Routine $\varphi-\mathrm{k}$ data for exploratory wells on the Alaska Peninsula were compiled from the State of Alaska Division of Oil \& Gas's (DOG) well files to augment data collected during this study. Additional previously-reported porosity and permeability data from Tertiary and Mesozoic outcrop samples (Reifenstuhl and others, 2005; Strauch and others, 2006) are included for comparison (table 4).

The samples are primarily from the upper Paleogene and Neogene portion of the stratigraphic section. They encompass the Oligocene Stepovak, Miocene Bear Lake (including the Unga Member), and Pliocene Milky River Formations (fig. 2). These units were purposefully chosen for initial investigation because of their high likelihood for containing reservoirs of good to excellent quality due to their relatively young age.

Detailed modal (point-count) analyses were performed on 47 samples to obtain quantitative estimates of detrital and authigenic mineralogies. X-ray diffraction (XRD) and scanning electron microscope (SEM) analyses were conducted on 19 samples to identify and quantify the clay mineralogy of the sandstones. The SEM micrographs are also useful for estimating the type and distribution of porosity and cements. This report is primarily intended to release these data in a timely manner for use in the evaluation of the basin's petroleum potential with the hope they might encourage future exploration. As such, detailed interpretation of the data and evaluation of regional trends of reservoir quality are limited. Recent work by DGGS documents various aspects of the structural geology, sedimentology, stratigraphy, and petroleum geology of Bristol Bay and the Alaska Peninsula (Reifenstuhl and others, 2005; Finzel and others, 2005; Decker and others, 2005; Strauch and others, 2006; Loveland and others, 2007).

\section{METHODS}

\section{THIN SECTIONS}

All samples were impregnated with bluedyed epoxy in a vacuum for 30 minutes followed by the application of high pressure (1,500-2,000 pounds per square inch or psi) for at least 8 hours. This procedure ensures complete impregnation of even the most impermeable samples and facilitates the recognition of pore types. All thin sections were stained for K-feldspar with potassium cobaltinitrate (Laniz and others, 1964) and for carbonates with a combination of alizarin red $\mathrm{S}$ and potassium ferricyanide (Dickson, 1965, 1966; Lindholm and Finkelman, 1972). Thin sections were prepared by Mark Mercer (Petrographic Services, Montrose, Colorado). Point-count analyses consisting of 300 points per sample for composition and 200 detrital grains for size were conducted by Michael D. Wilson (Wilson \& Associates, Lakewood, Colorado). Petrographic results are provided in tables 1 and 2 .

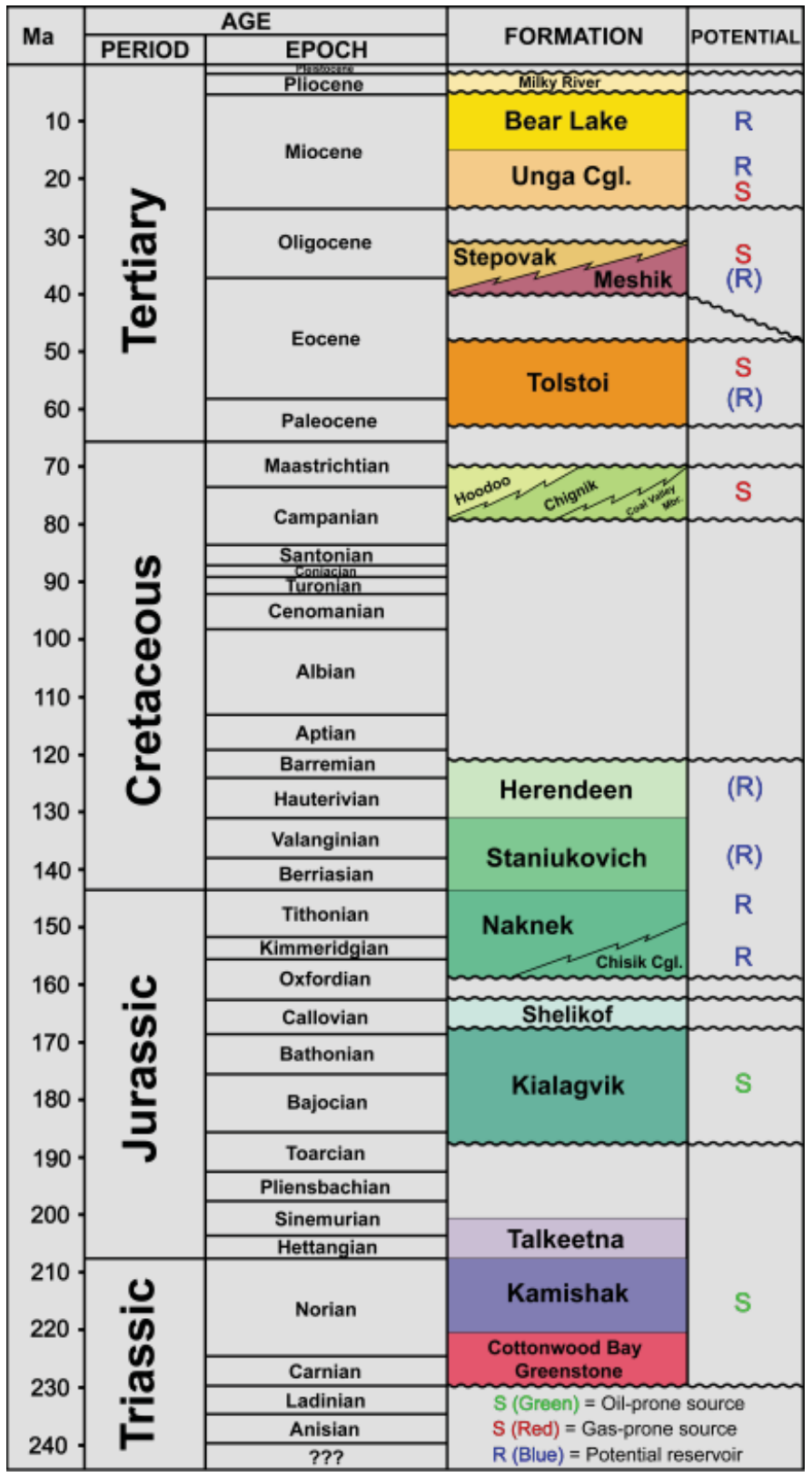

Figure 2. Composite stratigraphic column of Bristol Bay and the Alaska Peninsula (modified from Burk, 1965, and Detterman and others, 1996). 


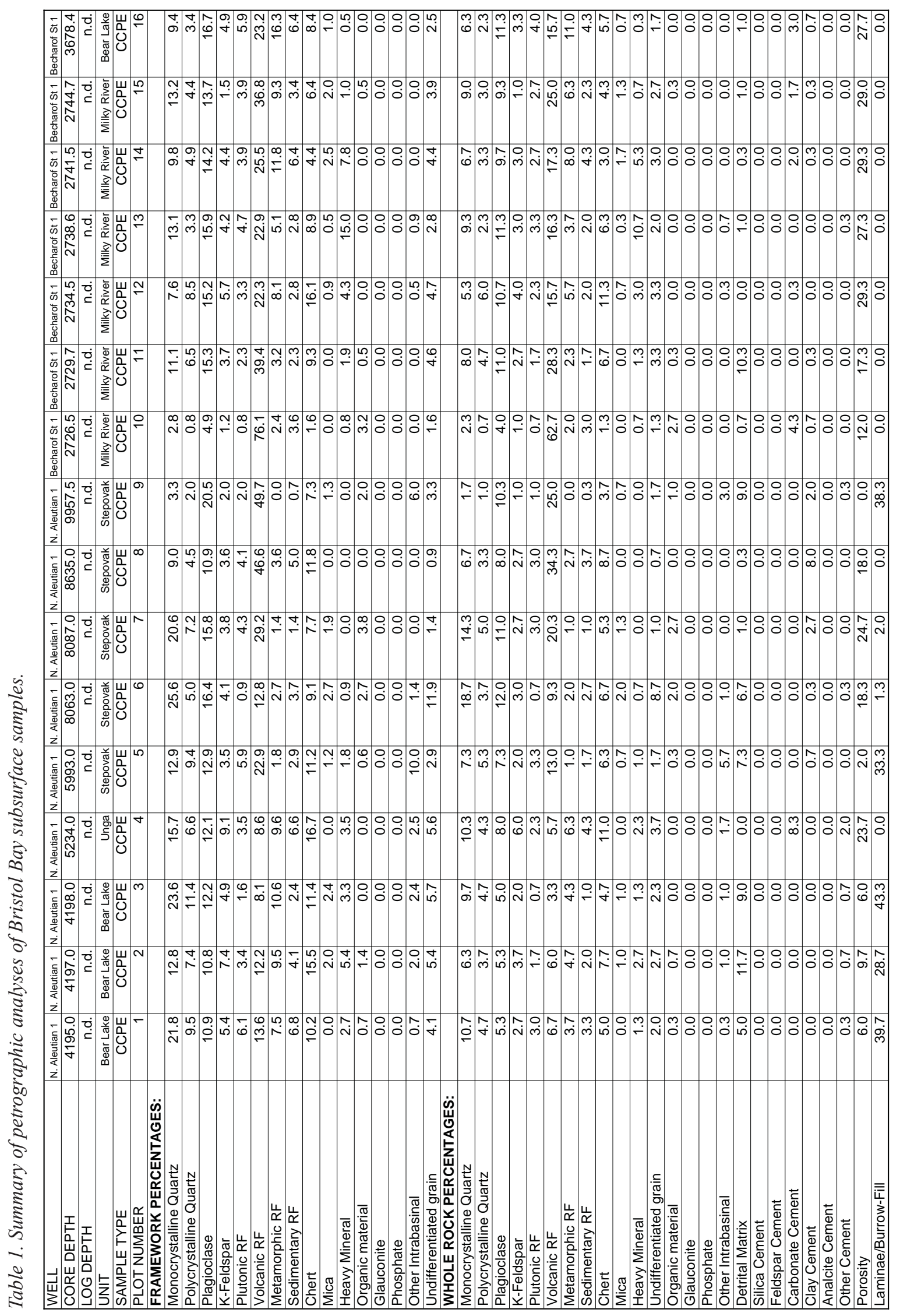




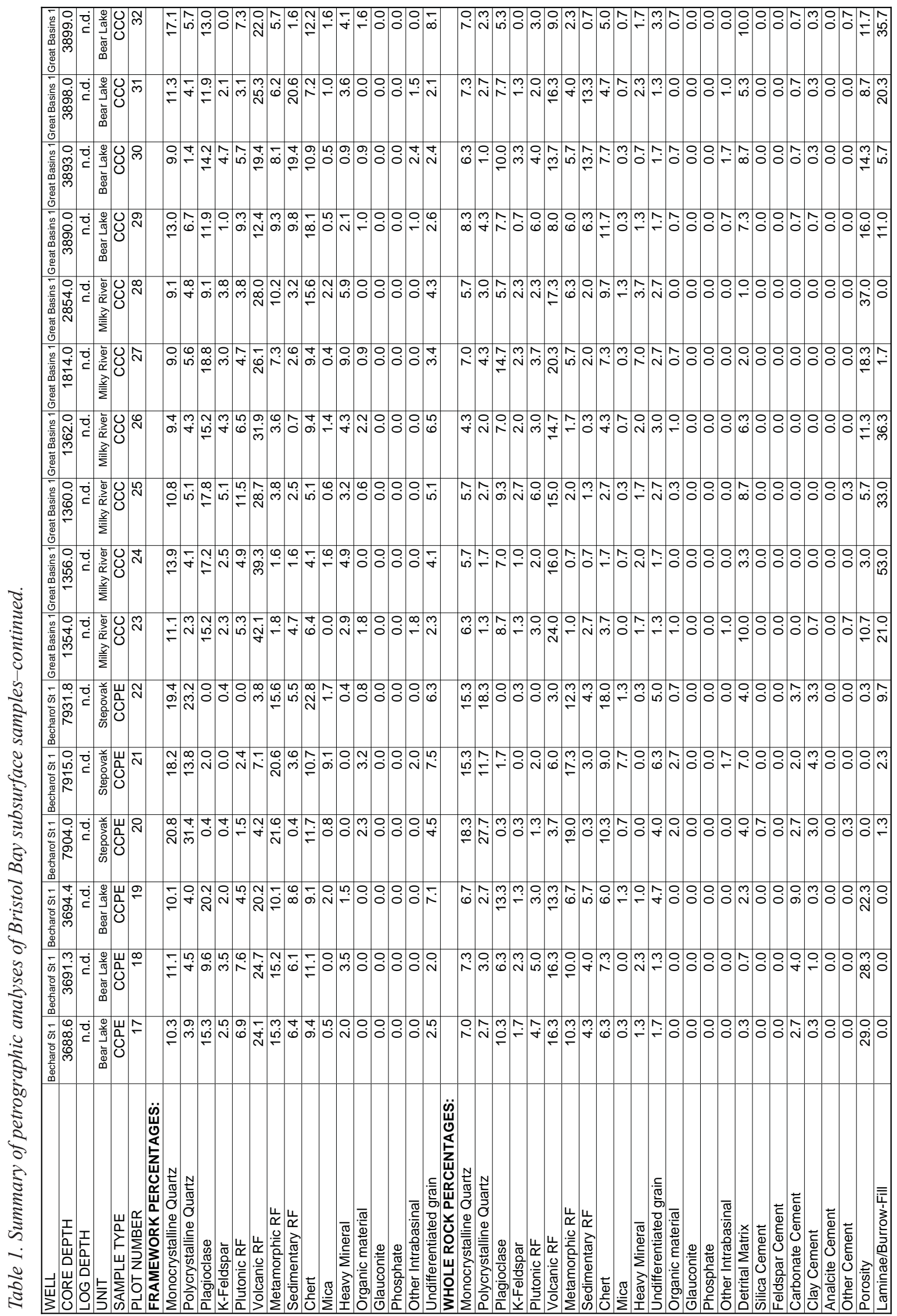




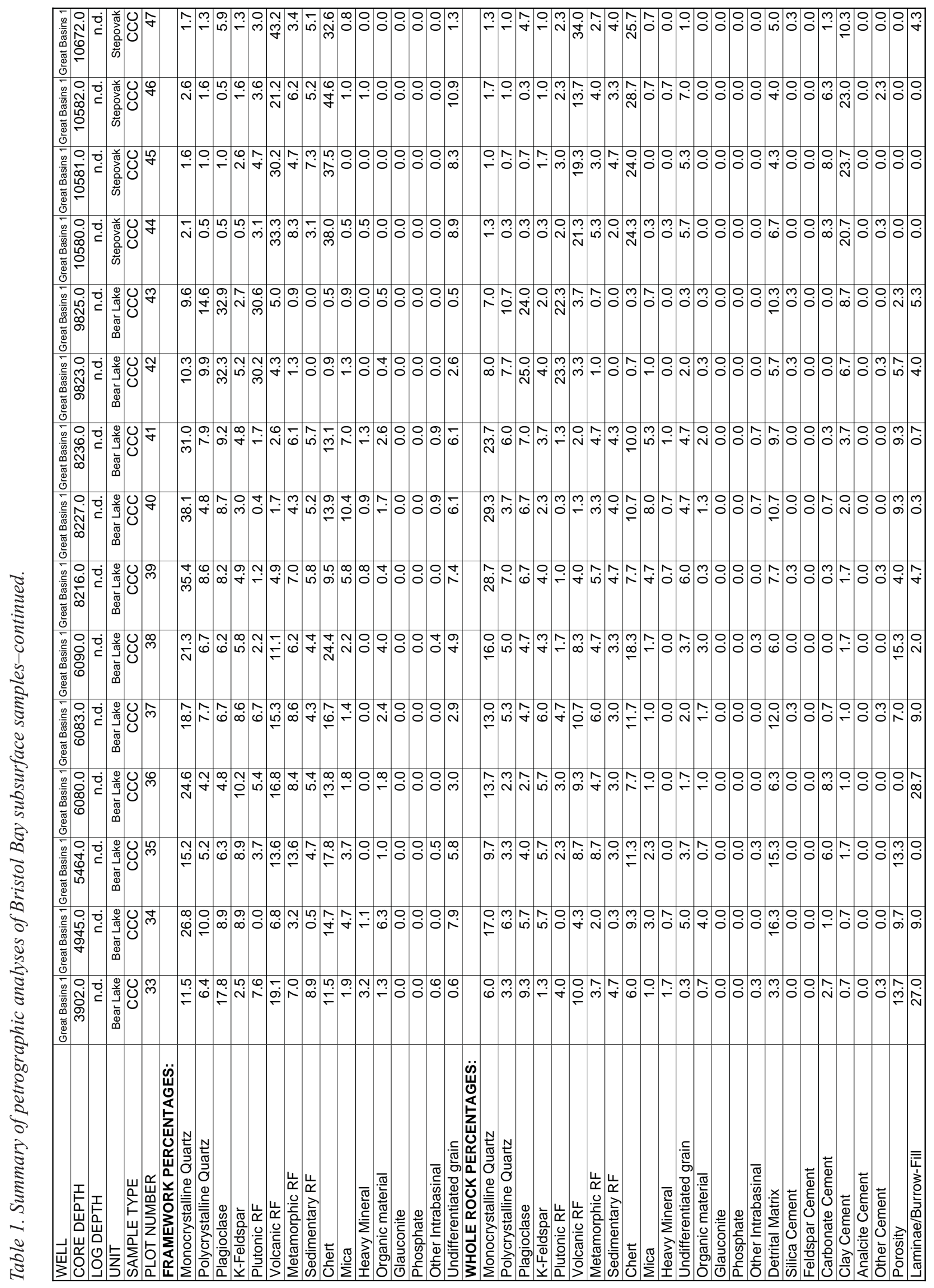




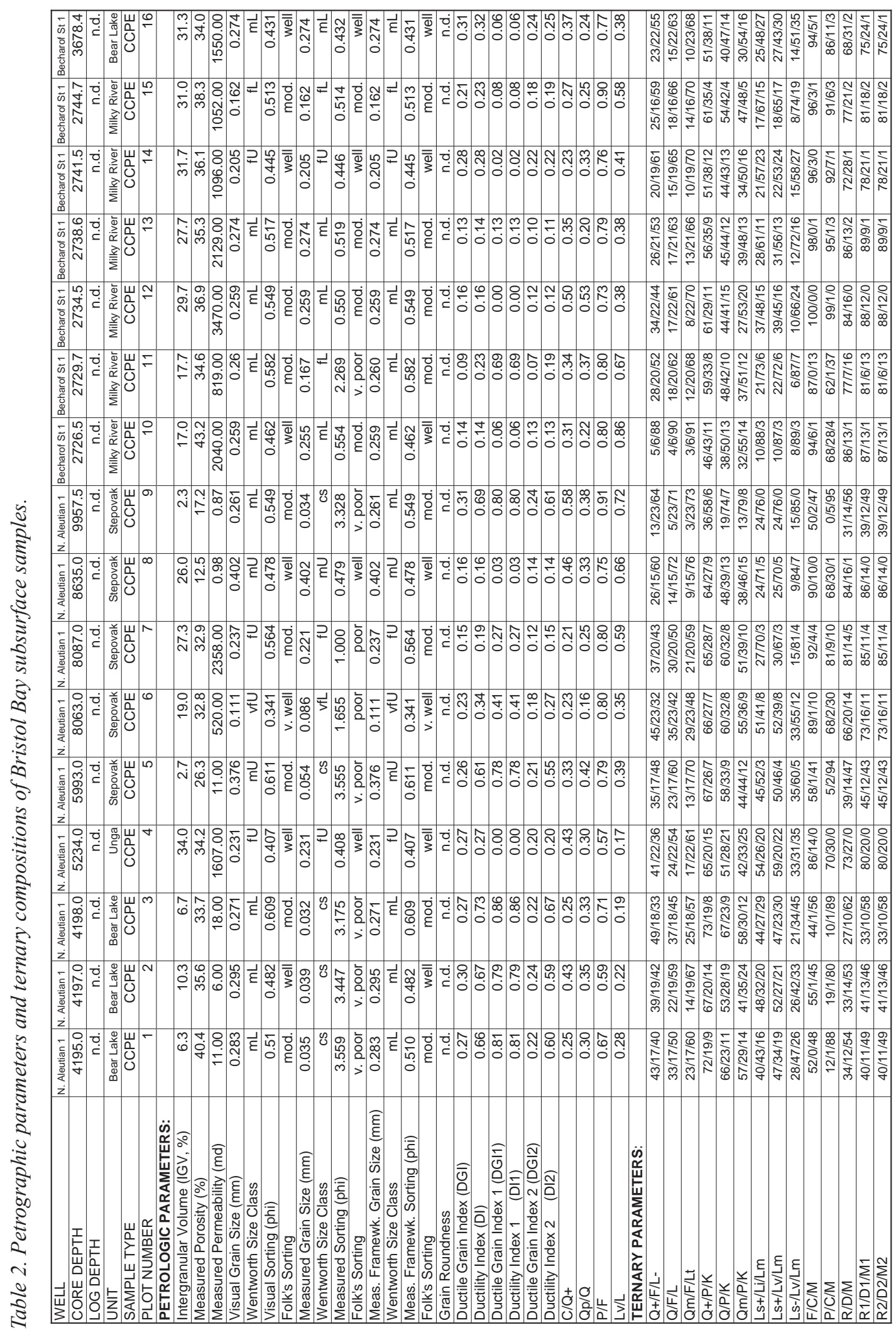




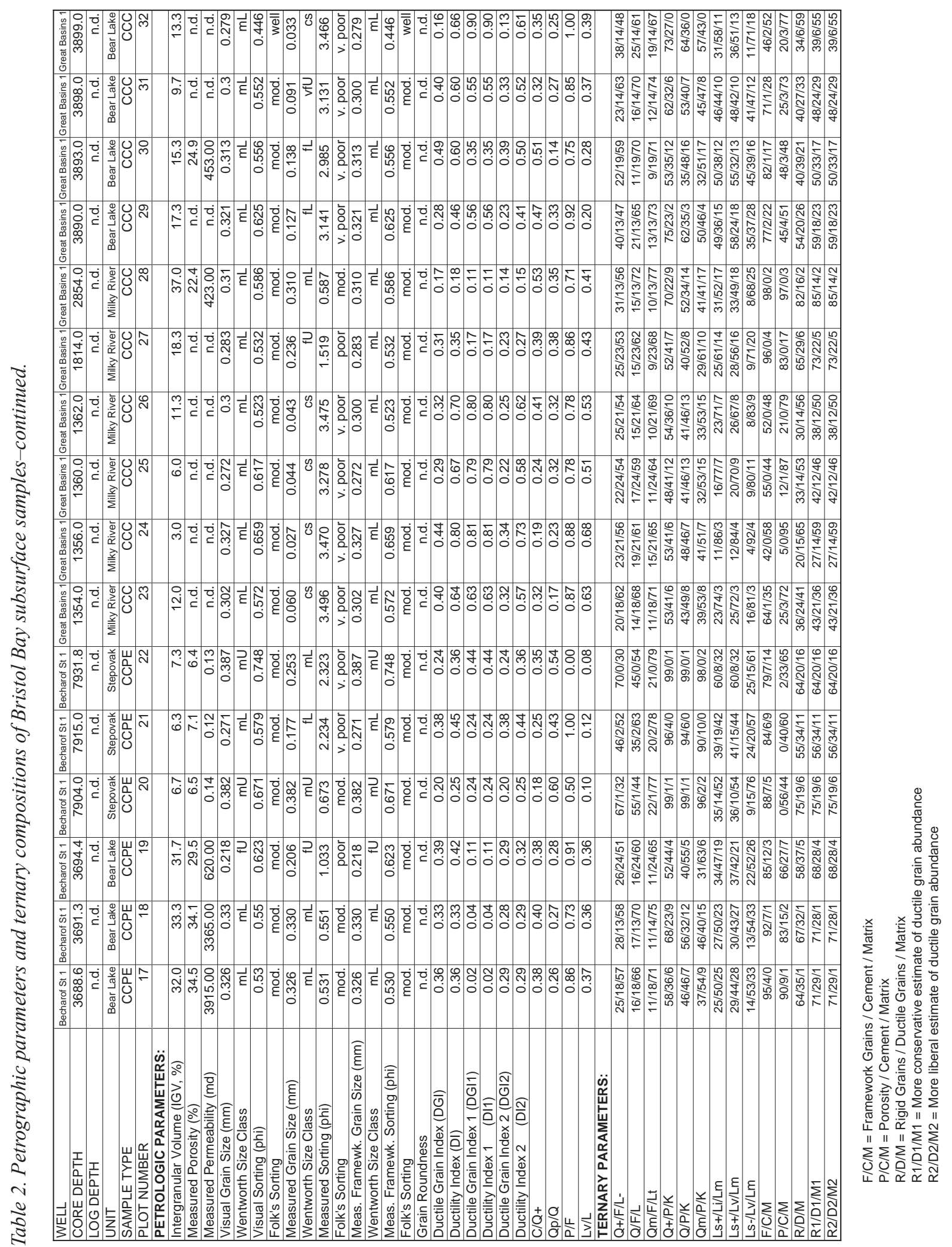




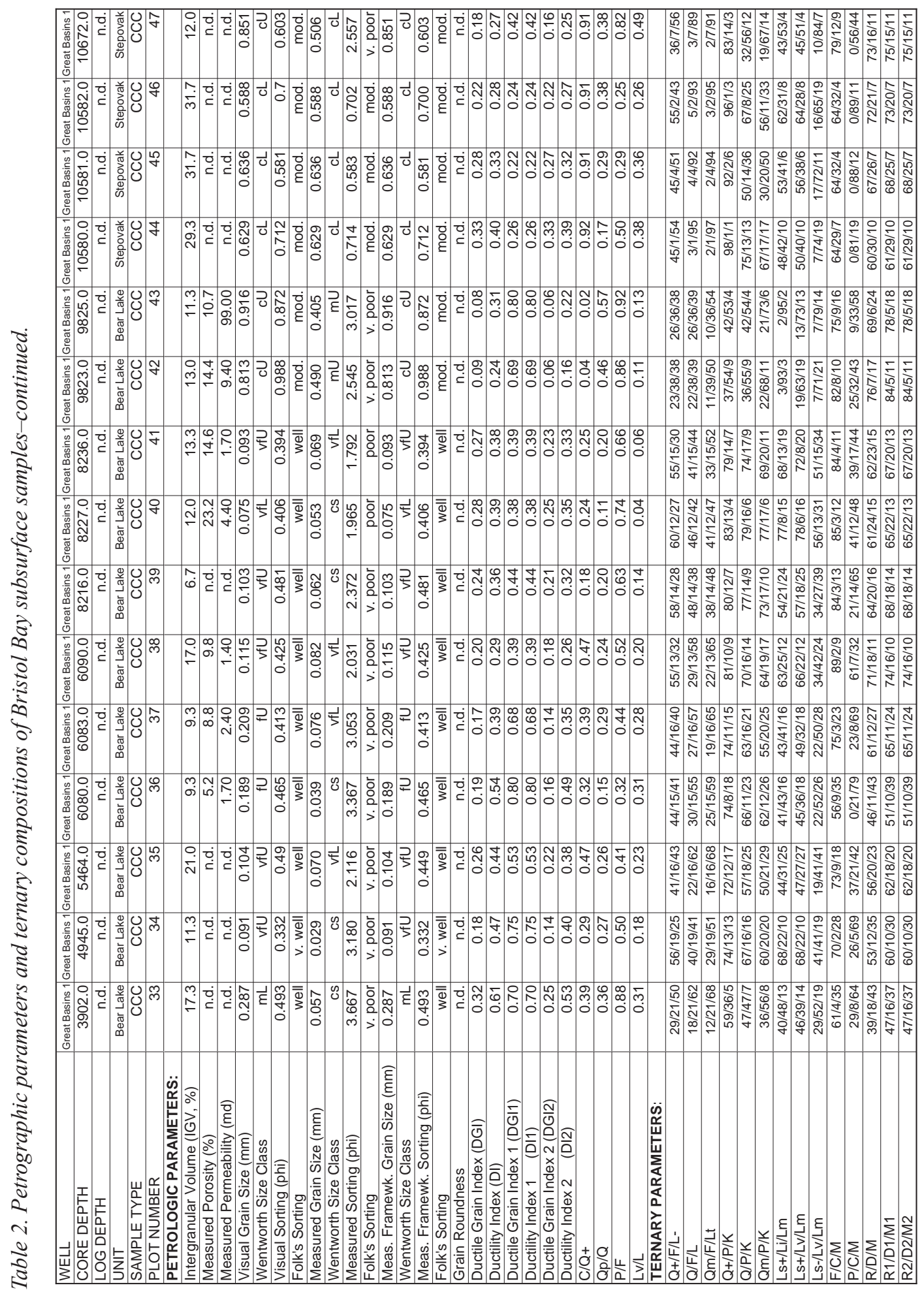




\section{X-RAY DIFFRACTION (XRD)}

Samples submitted for whole rock and clay mineral XRD analyses were cleaned of obvious contaminants and disaggregated in a mortar and pestle. A split of each sample was transferred to deionized water and pulverized using a McCrone micronizing mill. The resultant powder was dried, disaggregated, and pressure-packed into an aluminum sample holder to produce random whole-rock mounts. A separate split of each sample was dispersed in a dilute sodium phosphate solution using a sonic probe. The suspensions were centrifugally size fractionated to isolate clay-size $(<4$ micron equivalent spherical diameter) materials for a separate clay mount. A $<4$ micron cutoff was employed to include all authigenic clays, some of which, particularly kaolinite, are coarser than 2 microns. The suspensions were vacuumdeposited on nylon membrane filters to produce oriented clay mineral aggregates. Membrane mounts were attached to glass slides and exposed to ethylene glycol vapor for a minimum of 24 hours.

X-ray diffraction analyses of the samples were performed using a Rigaku automated powder diffractometer equipped with a copper $\mathrm{X}$-ray source $(40 \mathrm{kV}, 35 \mathrm{~mA})$ and a scintillation X-ray detector. The whole rock samples were analyzed over an angular range of 2 to $65^{\circ} 2 \Theta$ at a scan rate of one degree per minute. The glycol-solvated oriented clay mounts were analyzed over an angular range of 2 to $50^{\circ} 2 \Theta$ at a rate of $1.5^{\circ}$ per minute.

Semiquantitative determinations of whole-rock mineral amounts were obtained utilizing integrated peak areas (derived from peak-decomposition/profile-fitting methods) and empirical reference intensity ratio (RIR) factors determined specifically for the diffractometer used in data collection. The total phyllosilicate (clay and mica) abundance of the samples was determined on the whole-rock XRD patterns using combined $\{001\}$ and $\{\mathrm{hkl}\}$ clay mineral reflections and suitable empirical RIR factors.

X-ray diffraction (XRD) patterns from glycolsolvated clay-fraction samples were analyzed using techniques similar to those described above. The relative amounts of phyllosilicate minerals were determined from the patterns using profile-fitted integrated peak intensities and combined empirical and calculated RIR factors. Determinations of mixed-layer clay ordering and expandability were made by comparing experimental diffraction data from the glycol-solvated clay aggregates with simulated one-dimensional diffraction profiles generated using the program NEWMOD written by R.C. Reynolds (Moore and Reynolds, 1989). Sample preparation, analyses and interpretations were performed by James B. Talbot (K/T GeoServices, Inc., Argyle, Texas; see www.ktgeo.com for details of analytical procedure). $\mathrm{X}$-ray diffraction results are provided in table 3 .

\section{SCANNING ELECTRON MICROSCOPY (SEM)}

A split of sandstones that were X-rayed were also examined with an ISI DS-130 scanning electron microscope (SEM) to aid in the identification of authigenic components, particularly clay minerals, and to better visualize pore geometries (figs. 13-16). Standardless energy dispersive analyses of X-rays (EDX) were performed on several grains and pore-filling cements to confirm initial identifications based on crystal morphology. The analyses were conducted using a Kevex Delta 5 system attached to the SEM. This work was performed at the Advanced Instrumentation Laboratory, University of Alaska Fairbanks.

\section{RESULTS \\ INTERPRETATION OF TERNARY DIAGRAMS}

The composition of the sandstones determined via point-count analyses (tables 1 and 2) are summarized on a suite of ternary diagrams (fig. 3). The QFL (Quartz-Feldspar-Lithic) diagram (fig. 3A) is used to illustrate the composition of the major detrital components. In this diagram monocrystalline quartz $(\mathrm{Qm})$ and polycrystalline quartz (Qp) are apportioned to the Q-pole to highlight chemical and mechanical stability. All feldspars (potassium-feldspar and plagioclase) are apportioned to the F-pole, with the remaining lithic components (including chert) plotted at the L-pole. Chert is included with the lithics to emphasize its sedimentary origin. In a break from tradition (Dickinson, 1970; Dickinson and Suczek, 1979), intrabasinal components (that is, glauconite, phosphate, and pellets) are included with the lithics due to their potential for compaction, which negatively affects reservoir quality. In this diagram, the closer a sandstone plots towards the Q-pole, the greater its mineralogical maturity. The QmPK diagram (fig. 3B) is intended to show the composition of the monocrystalline components (quartz and feldspar) of the rocks, therefore all lithic fragments (including $\mathrm{Qp}$ ) are excluded from the diagram. As in the QFL diagram, the closer a sandstone plots towards the Q-pole, the greater its mineralogical maturity.

The LsLvLm diagram (fig. 3C) shows the composition of the aphanitic polycrystalline (lithic) components of the rock. Sedimentary rock fragments (SRF) including chert are included at the Ls-pole. Volcanic rock fragments (VRF) are apportioned to the Lv-pole, while metamorphic rock fragments (MRF) are included at the Lm-pole. Phaneritic plutonic rock fragments (for example, granite and diorite) are excluded from this diagram. The PCM diagram (fig. 3D) portrays the 


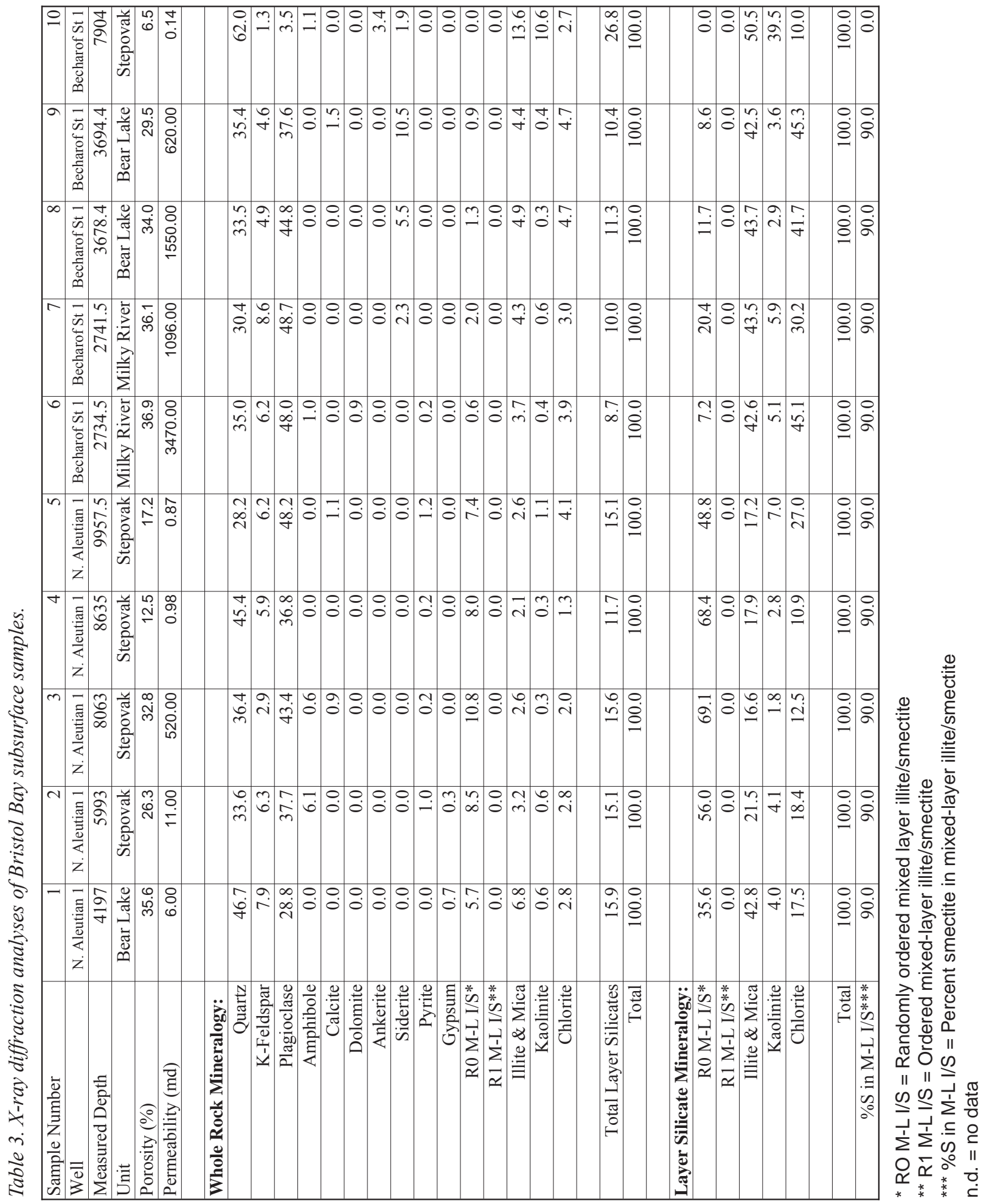




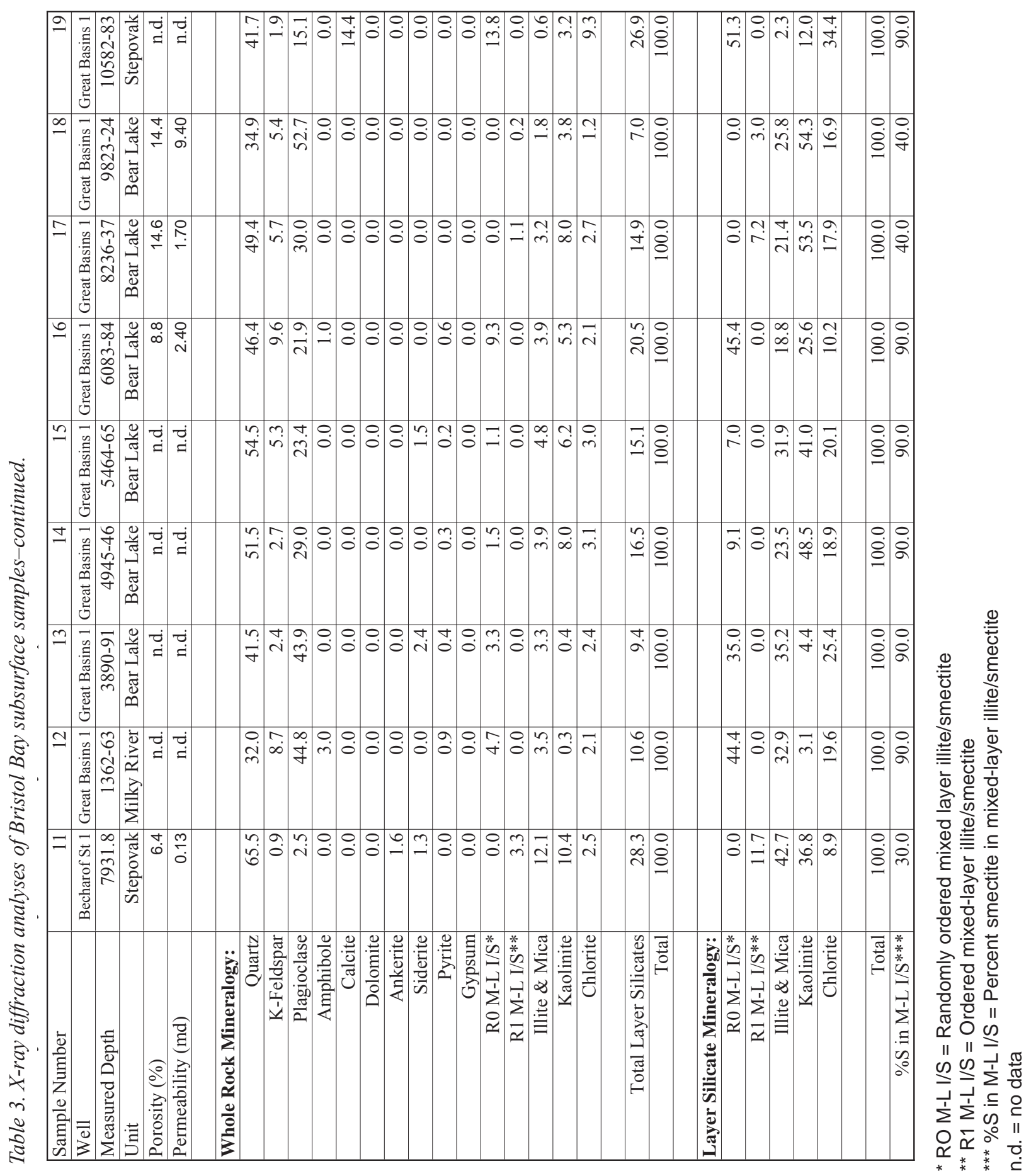




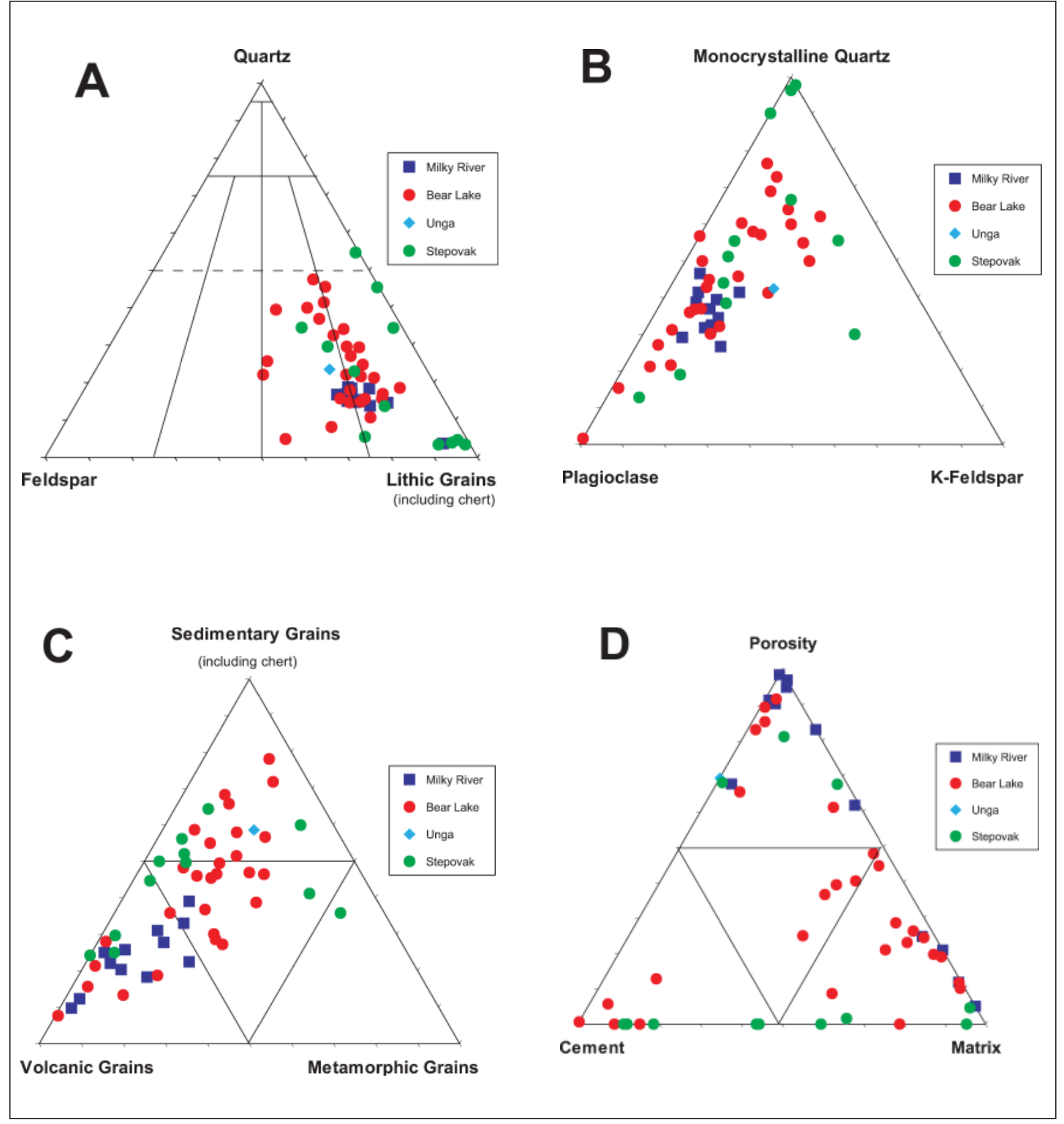

Figure 3. Ternary diagrams showing composition of Bristol Bay sandstones. A. QFL (Quartz-Feldspar-Lithics) diagram showing composition of detrital grains comprising the rock framework. All the sandstones are enriched in lithic grains. B. QmPK (Monocrystalline Quartz-Plagioclase-K-Feldspar) diagram showing monocrystalline composition of Bristol Bay sandstones. The sandstones are enriched in quartz and plagioclase with relatively less K-Feldspar. C. Ls $+L v L m$ (Sedimentary Lithics +Chert-Volcanic Lithics-Metamorphic Lithics) diagram showing lithic composition of Bristol Bay sandstones. Milky River sandstones are typically enriched in volcanic lithics. D. PCM (Porosity-Cement-Matrix) diagram showing composition of the intergranular components of the sandstones. Detrital matrix is present in some of the sandstones and is a primary factor controlling permeability in those rocks. Tables 1 and 2 list all data included in these diagrams. 
composition of the intergranular components (that is, porosity, cements, and matrix) of the rock. The higher the ratio of porosity to cement plus matrix, the better the reservoir quality of the rock.

\section{TERTIARY SANDSTONES}

The Tertiary sandstones vary in grain size from lower very fine grained (fL, $70 \mu \mathrm{m}$ ) to upper coarsegrained $(\mathrm{cU}, 920 \mu \mathrm{m})($ table 2$)$. The framework grains are moderately to very well sorted $(0.33-0.99$ standard deviation in phi units of just the framework grains; Measured Framework Sorting in table 2) but the presence of detrital matrix results in some rocks having very poor overall sorting $(>2.0$ standard deviation in phi units of entire rock, framework grains + matrix; Measured Sorting in table 2). In general, the finer-grained sandstones tend to be better sorted (fig. 4). The sandstones are highly lithic with an average framework composition of $\mathrm{Q}_{22} \mathrm{~F}_{16} \mathrm{~L}_{61}$ (fig. 3A). Monocrystalline quartz (Qm, 15 percent) is more common than polycrystalline (Qp, 7 percent) varieties. Feldspar is common with plagioclase (12 percent) dominant over K-feldspar (4 percent). The average lithic composition of the sandstones is $\mathrm{Ls}_{41} \mathrm{Lv}_{43} \mathrm{Lm}_{16}$ with grains consisting of felsic and mafic volcanic fragments, chert, phyllite, schist, quartzite, felsic plutonic fragments, mudstone, and siltstone (table 1). The Milky River samples are more volcanogenic than the other Tertiary sandstones with an average composition of $\mathrm{Ls}_{24} \mathrm{Lv}_{65} \mathrm{Lm}_{11}$. Micas average 2 percent of the framework fraction and consist of chlorite, muscovite, and biotite. Amphibole, pyroxene, epidote, and garnet are the most common heavy minerals and are indicative of an immature, labile suite.

Detrital matrix varies in abundance, comprising from 0 to 16 percent of the sandstones (table 1). It is particularly common in many of the Bear Lake samples (fig. 3D). The matrix consists predominantly of clay minerals with lesser amounts of detrital silt. Clay laminae are common in many of the samples, particularly the Milky River and Bear Lake sandstones (table 1). Together, detrital matrix and clay laminae account for more than 40 percent of the bulk volume of several sandstones. $\mathrm{X}$-ray diffraction analyses suggest these clays largely consist of illite and mixed-layer illite/smectite (table 3). The mixed-layer clay consists dominantly of smectite with only 10 percent illite layers. Because these clays are highly smectitic, the matrix could exhibit significant swelling if exposed to fresh water.

The majority of the sandstones generally lack significant cement (table 1; figs. 7-12). Quartz cement occurs in minor amounts in a few samples, due in part to the lack of nucleation sties and relatively low abundance of detrital quartz. The extensive matrix in some of the samples also retards cementation by inhibiting nucleation of overgrowths. Carbonate cement, particularly siderite and calcite, occur in variable amounts (up to 10.5 percent of bulk rock) in a few samples but generally has little effect on reservoir quality in the majority of samples. Authigenic, pore-filling kaolinite (fig. 15) occurs in several samples and is probably related to feldspar altera-

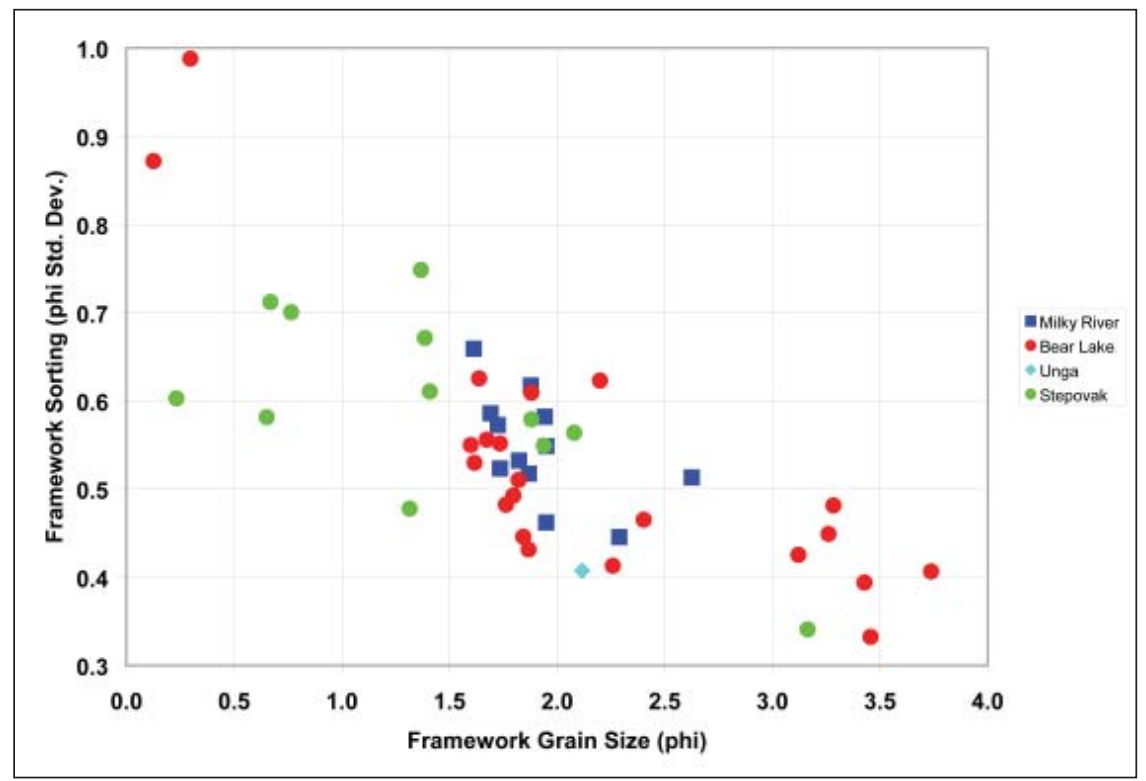

Figure 4. Grain size-sorting scatter plot of Bristol Bay sandstones by formation. Data are for grains greater than $30 \mu \mathrm{m}$ in diameter and therefore exclude clay and very fine to medium silt. In general, the finer-grained rocks tend to be better sorted (note grain size is shown in phi units). Pearson correlation coefficient is -0.77 . 
tion. In a few sandstones where it comprises more than 10 percent of the rocks, kaolinite significantly degrades reservoir quality. Representative photomicrographs are presented in figures 7-12.

\section{RESERVOIR QUALITY}

Reservoir quality of the Tertiary sandstones varies from excellent $(\varphi>30$ percent, $k>100 \mathrm{md})$ to poor $(\varphi<10$ percent, $\mathrm{k}<1 \mathrm{md})$. In order to illustrate the regional porosity-permeability trend, data for Tertiary and Mesozoic sandstones were plotted together (fig. 5). Most of the high-quality sandstones are Tertiary subsurface samples; the majority of low-quality rocks are from Mesozoic outcrops. Using an economic cutoff of 10 percent porosity and $1 \mathrm{md}$ permeability (suitable for liquid hydrocarbons), the majority of samples could be effective hydrocarbon reservoirs. Using lower $\varphi-\mathrm{k}$ cutoffs ( 7 percent porosity and $0.1 \mathrm{md}$ permeability), a significant number of additional samples could be effective gas reservoirs.
There is a fairly systematic relationship between reservoir quality (porosity-permeability) and depth (fig. 6). Porosities in excess of 20 percent and permeabilities higher than $10 \mathrm{md}$ are present at depths approaching 10,000 feet. It should be noted that much of the data are from the North Aleutian COST \#1 well that was drilled offshore in a deep portion of the basin. It is unclear if similar trends exist for the shallower, onshore portion of the basin. Additional data are needed before regional porosity-depth and permeability-depth trends can be established with certainty.

\section{CONCLUSION}

Based on detailed point-count analyses, conventional core analyses, and SEM examination of samples from three exploratory wells, sandstones with favorable reservoir properties are present in the Milky River, Bear Lake, and Stepovak Formations and may yield economically viable petroleum reservoirs. Sandstones in older, more deeply buried strata are likely to be of lower reservoir quality.

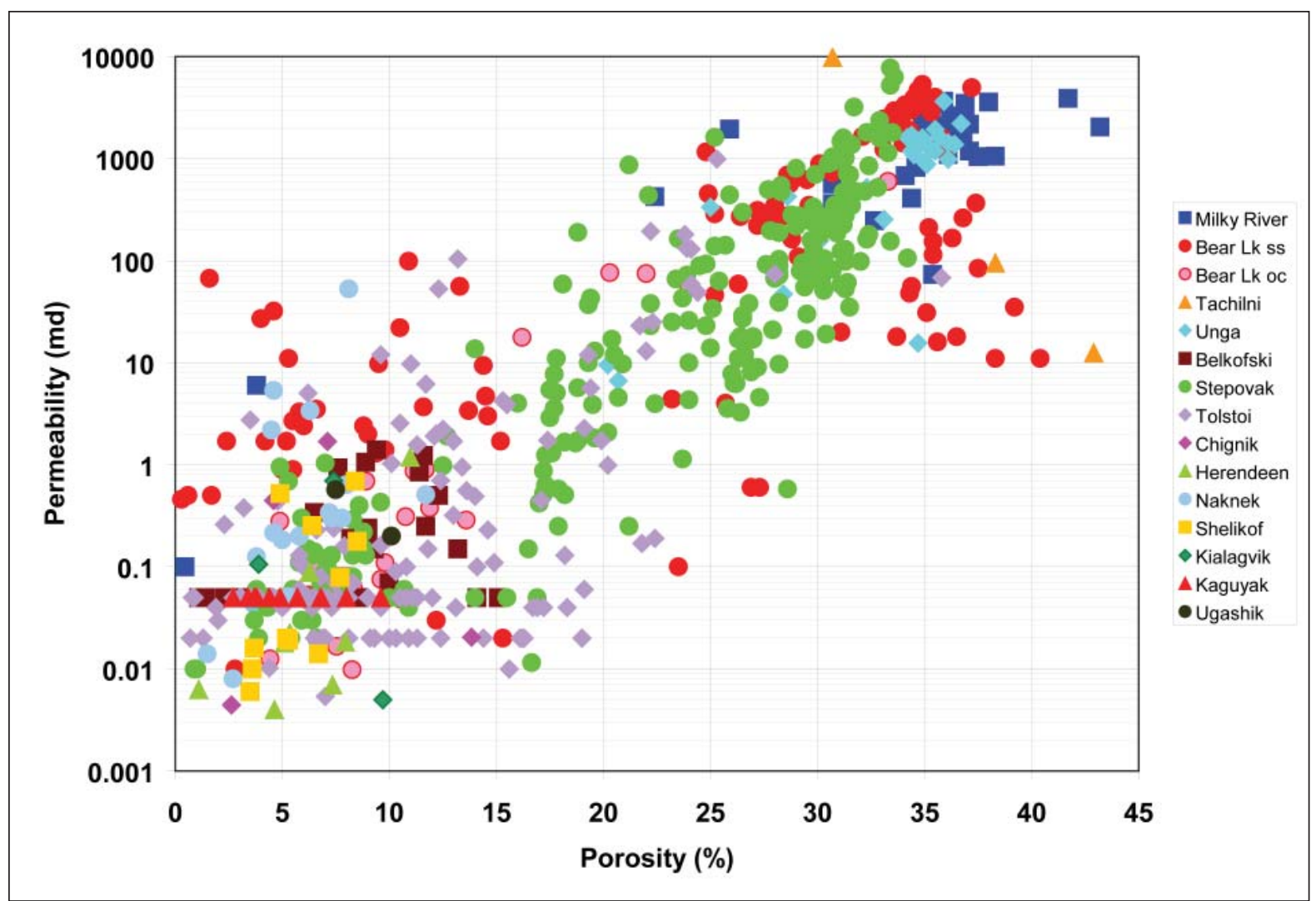

Figure 5. Porosity-permeability scatter plot of Bristol Bay sandstones by formation. Using a cutoff of 10 percent porosity and $1 \mathrm{md}$ permeability, a large proportion of the samples have good to excellent reservoir quality. Most of the high-quality rocks are Tertiary subsurface samples while the majority of low-quality rocks are from Mesozoic outcrops. Table 4 lists all data included in this plot. 


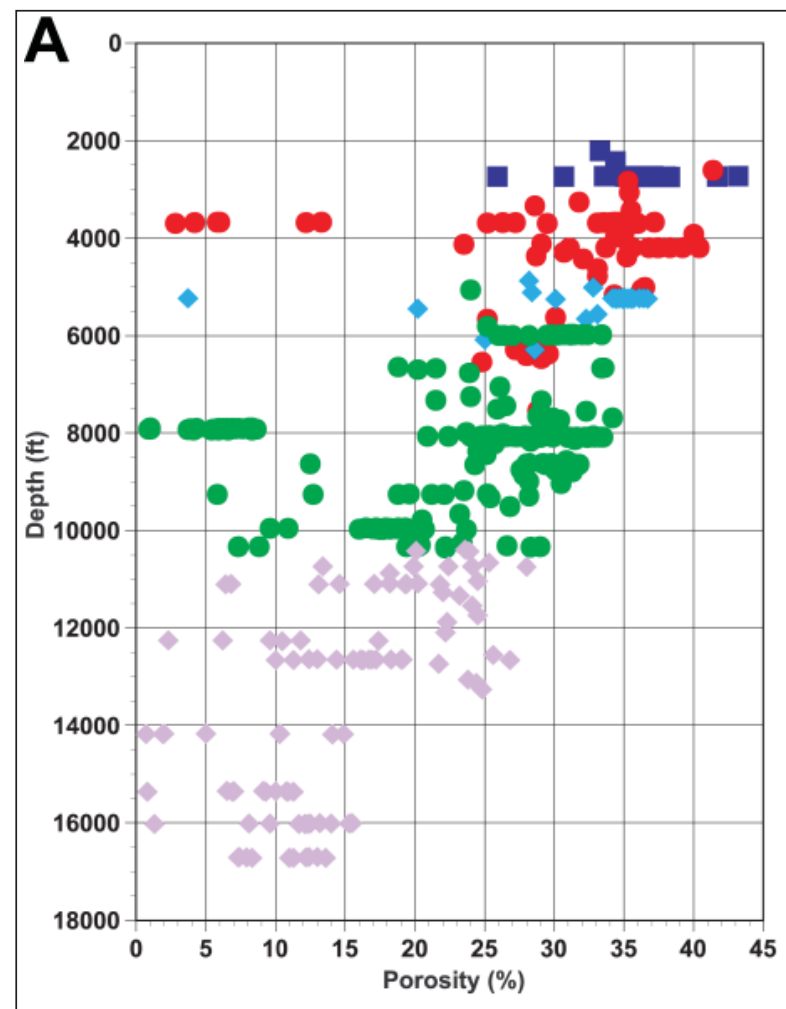

Milky River Bear Lake Unga Stepovak $\diamond$ Tolstoi

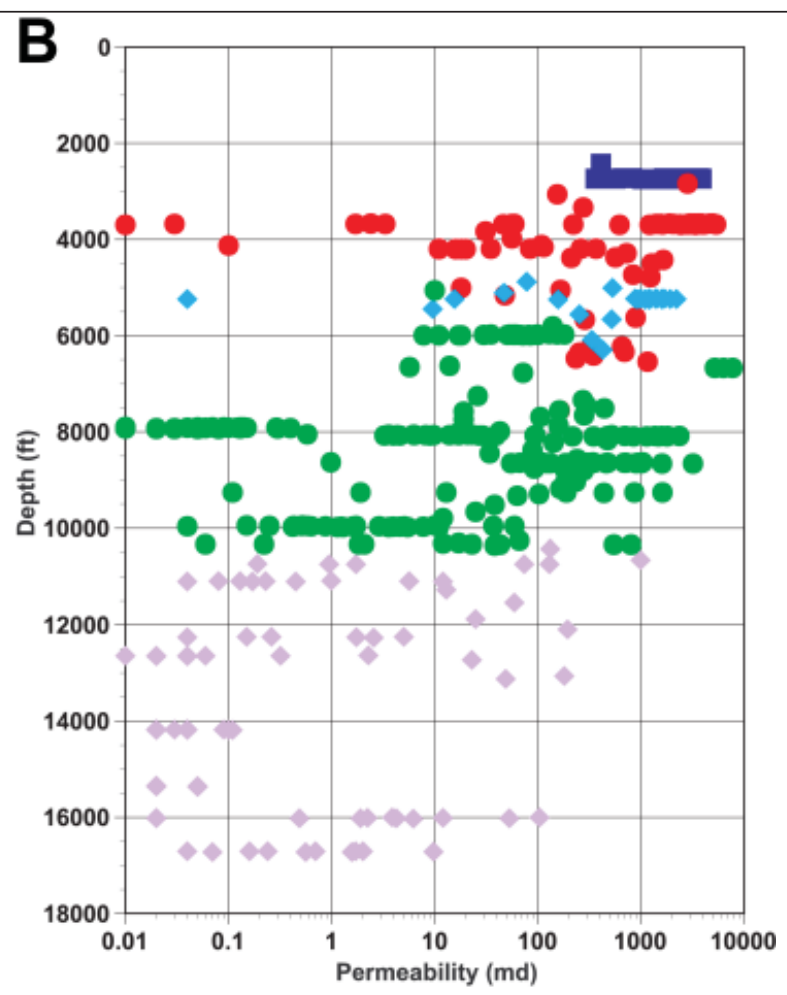

Milky River Bear Lake Unga Stepovak $\bullet$ Tolstoi

Figure 6. Reservoir quality-depth scatter plots of Bristol Bay sandstones by formation. A. Porosity-depth trend. B. Permeability-depth trend. Table 4 lists data included in this plot.

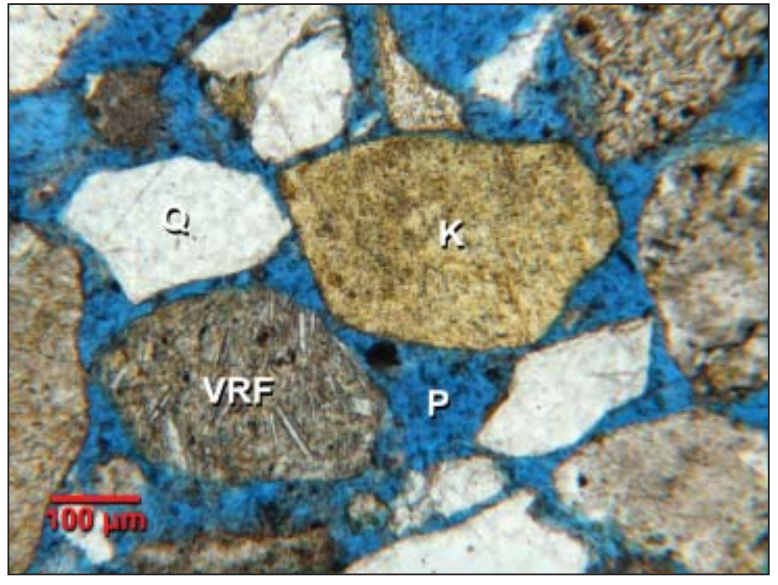

Figure 7. Photomicrograph of Milky River sandstone showing well-developed intergranular porosity $(P)$. Framework grains include quartz (Q), K-feldspar $(K)$, and volcanic rock fragments (VRF). Becharof State \#1, 2,734.5', $\varphi=$ 36.9 percent, $k=3,470 \mathrm{md}$.

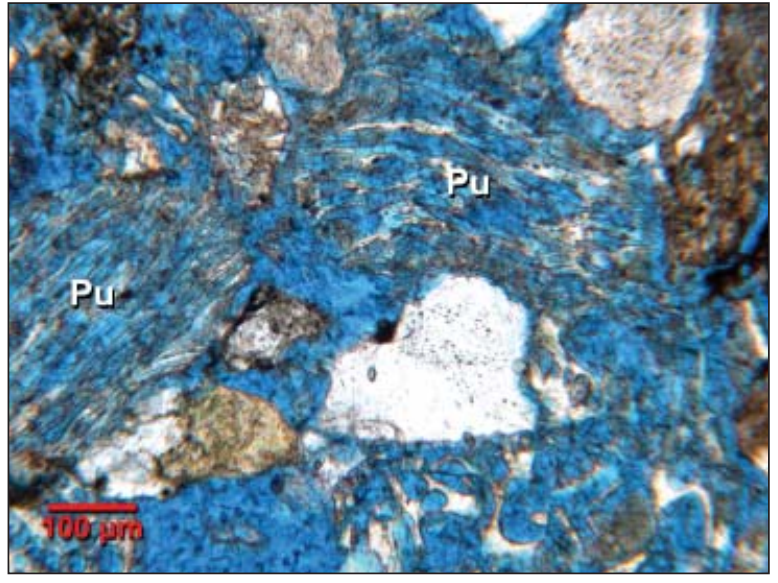

Figure 8. Photomicrograph of Milky River sandstone showing substantial mesoporosity in vesicular pumice fragments (Pu). Becharof State \#1, 2,726.5', $\varphi=43.2$ percent, $k=$ 2,040 md. Sample contains much pumice. 


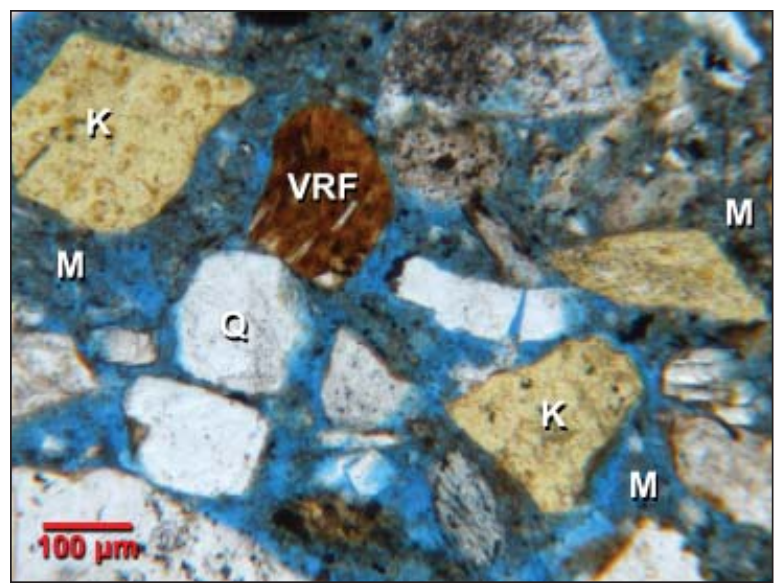

Figure 9. Photomicrograph of Bear Lake sandstone showing detrital clay matrix (M) partially occluding intergranular pores. Framework grains include quartz (Q), K-feldspar $(K)$, and volcanic rock fragments (VRF). North Aleutian COST \#1, 4,197.0', $\varphi=35.6$ percent, $k=16 \mathrm{md}$. Low permeability is the result of extensive clay matrix.

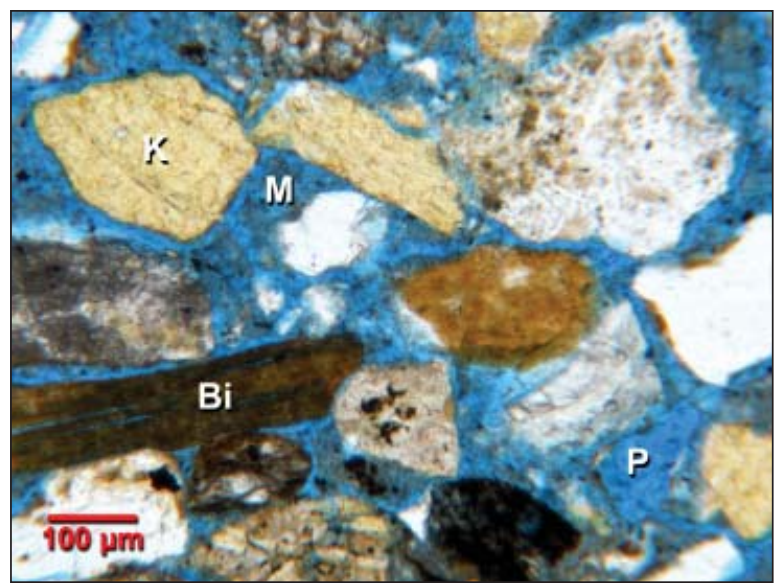

Figure 10. Photomicrograph of Bear Lake sandstone showing clay matrix $(M)$ sporadically filling intergranular pores (P). Framework grains include $K$-feldspar $(K)$ and biotite (Bi). North Aleutian COST \#1, 2,734.5', $\varphi=33.7$ percent, $k=18 \mathrm{md}$. Low permeability is the result of extensive clay matrix.

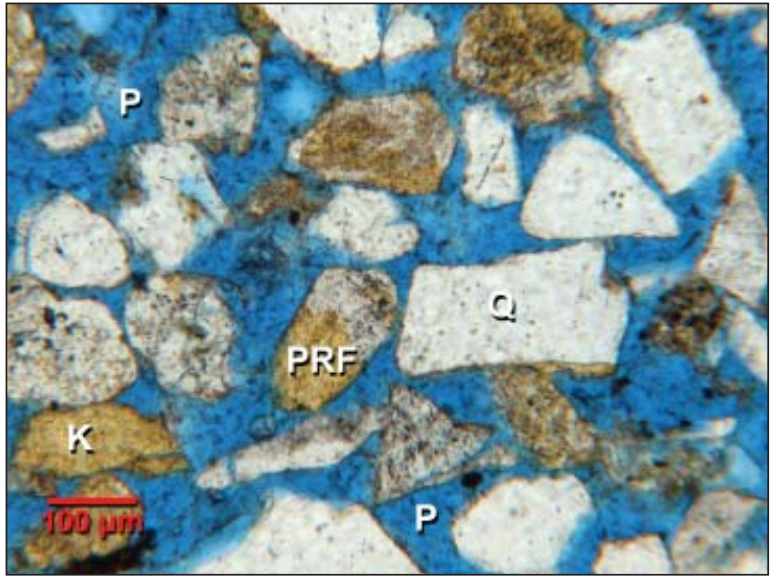

Figure 11. Photomicrograph of Stepovak sandstone showing well-developed intergranular porosity $(P)$. Framework grains include quartz (Q), K-feldspar (K), and plutonic rock fragments (PRF). North Aleutian COST \#1, 8,087.0', $\varphi=32.9$ percent, $k=2,358 \mathrm{md}$.

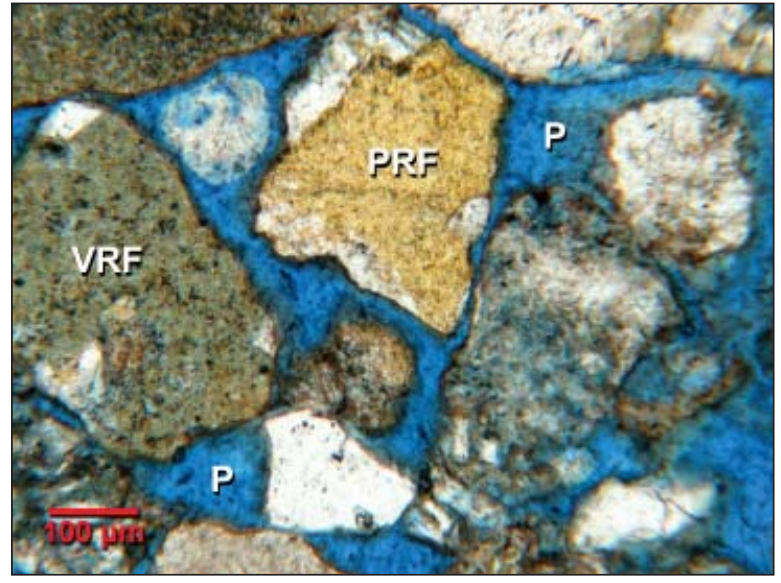

Figure 12. Photomicrograph of Stepovak sandstone showing both point and long contacts between grains. Intergranular porosity $(P)$ is common. Framework grains include volcanic (VRF) and plutonic (PRF) rock fragments. North Aleutian COST \#1, 8,635.0', $\varphi=31.4$ percent, $k=709 \mathrm{md}$. 


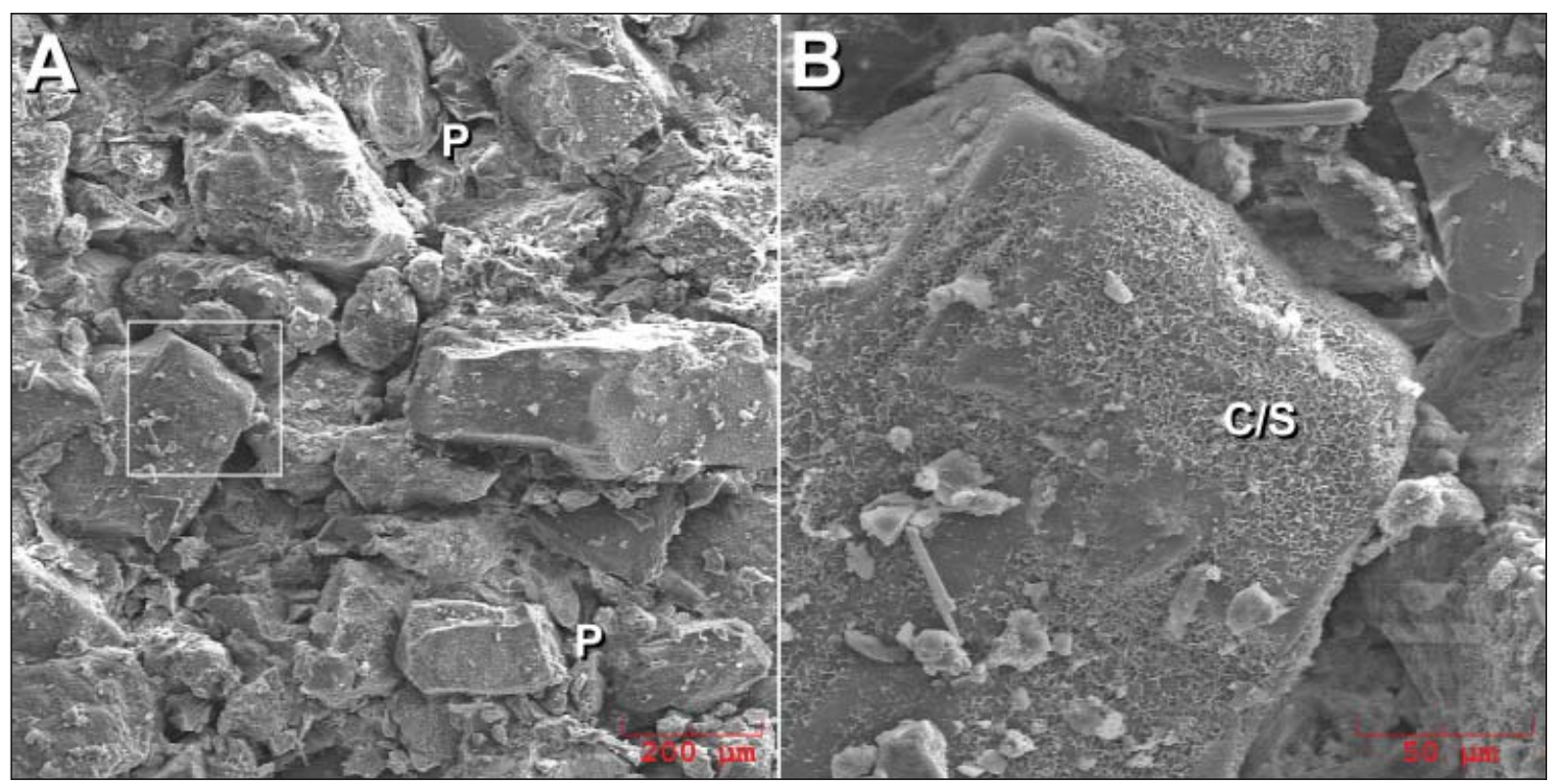

Figure 13. SEM photomicrograph of sandstone from the Milky River Formation, Amoco Becharof State \#1, 2, 735.5'. A. General view showing angular nature of detrital grains and abundant intergranular porosity $(P)$. B. Enlarged view of outlined area showing authigenic clay, probably mixed-layer chlorite-smectite (C/S), coating detrital grain.

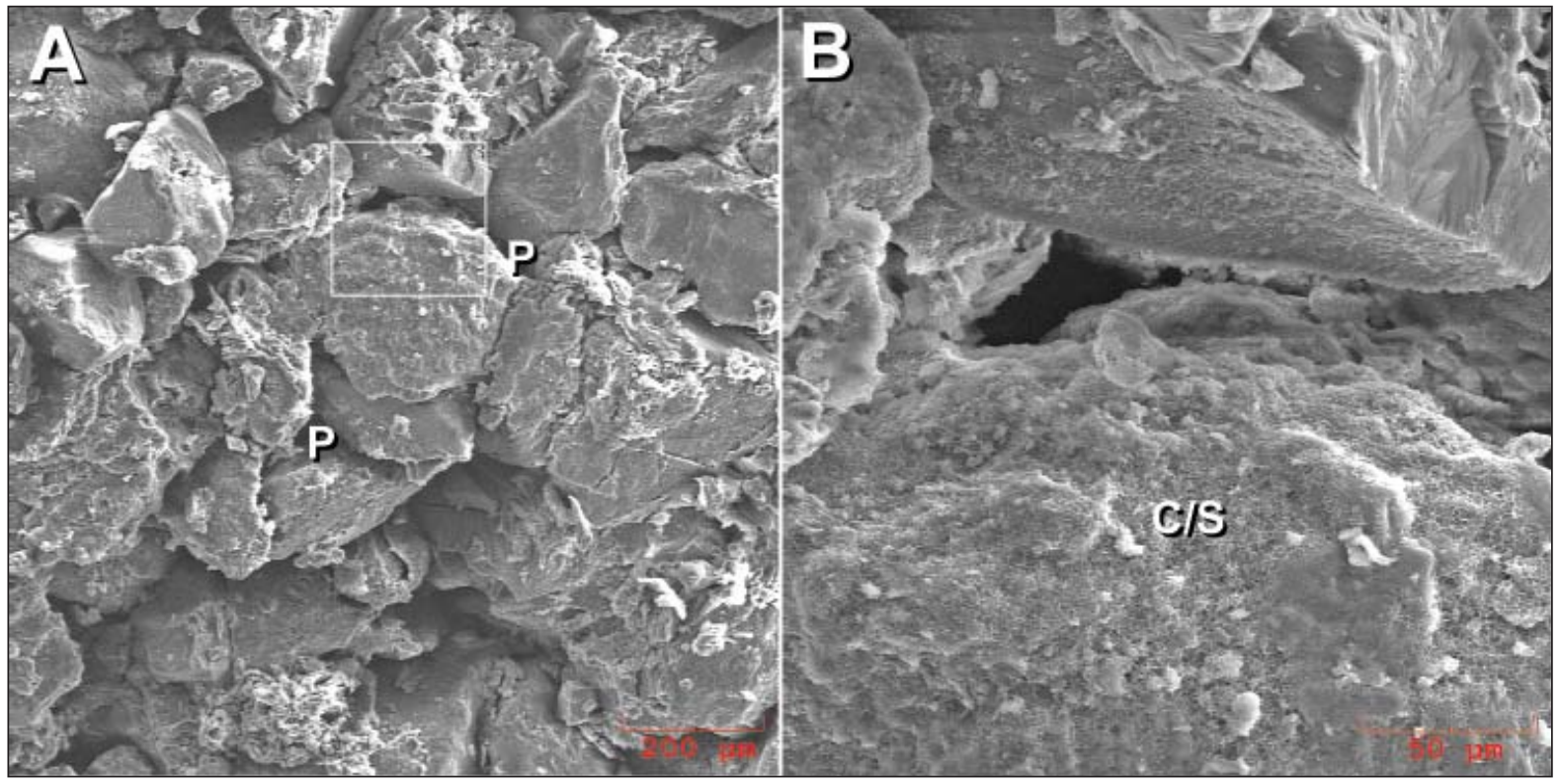

Figure 14. SEM photomicrograph of sandstone from the Bear Lake Formation, Amoco Becharof State \#1, 3, 678.4'. A. General view showing abundant intergranular pores connected by open pore throats $(P)$. B. Enlarged view of outlined area showing authigenic clay, probably mixed-layer chlorite-smectite $(C / S)$, coating detrital grain and lining intergranular pore. 


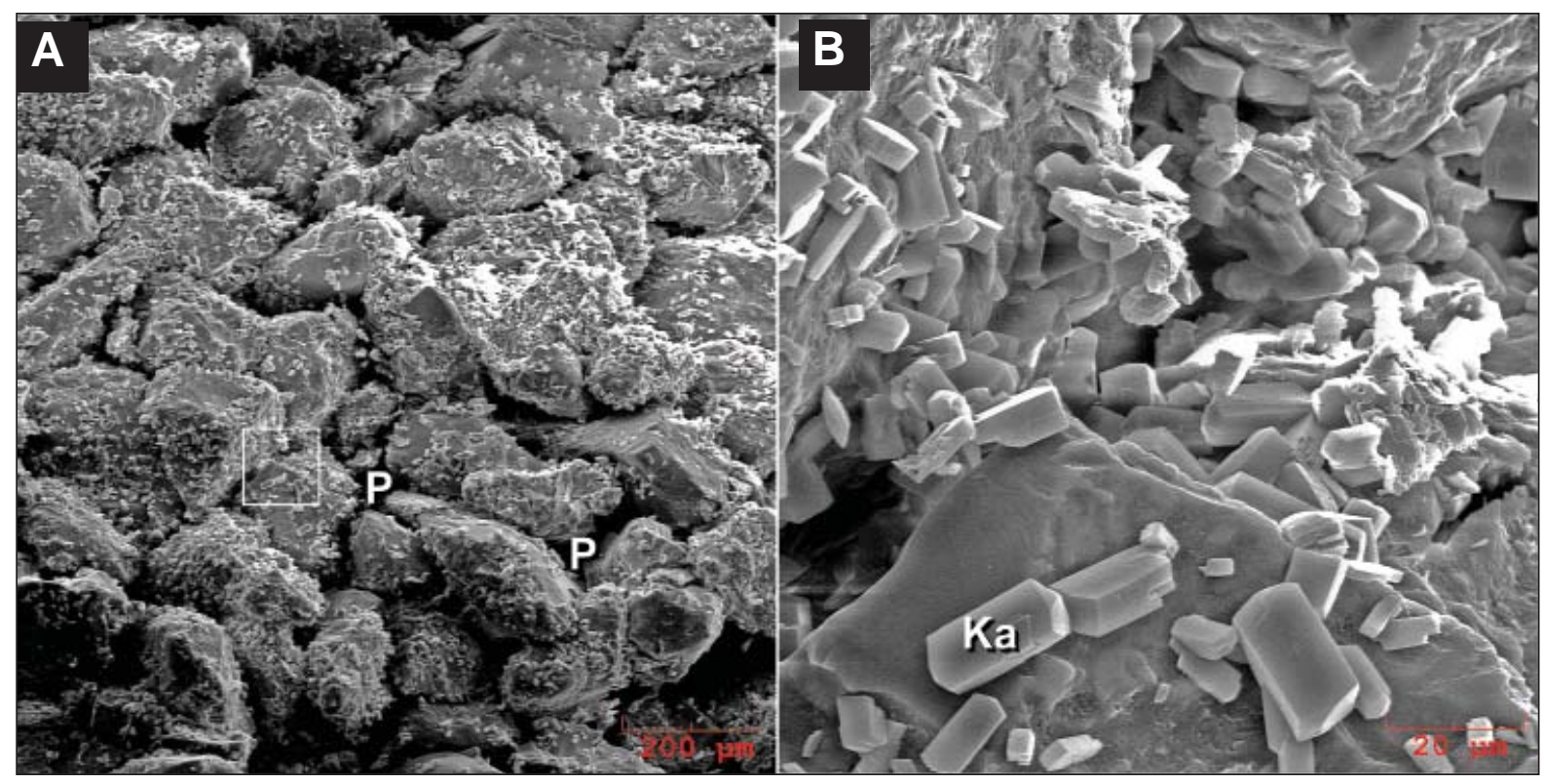

Figure 15. SEM photomicrograph of sandstone from the Unga Formation, ARCO North Aleutian COST \#1, 5,234.0'. A. General view showing abundant intergranular porosity $(P)$ and detrital grains coated with kaolinite. B. Enlarged view of outlined area showing authigenic kaolinite (Ka) filling intergranular pore. Microporosity is common between clay platelets.

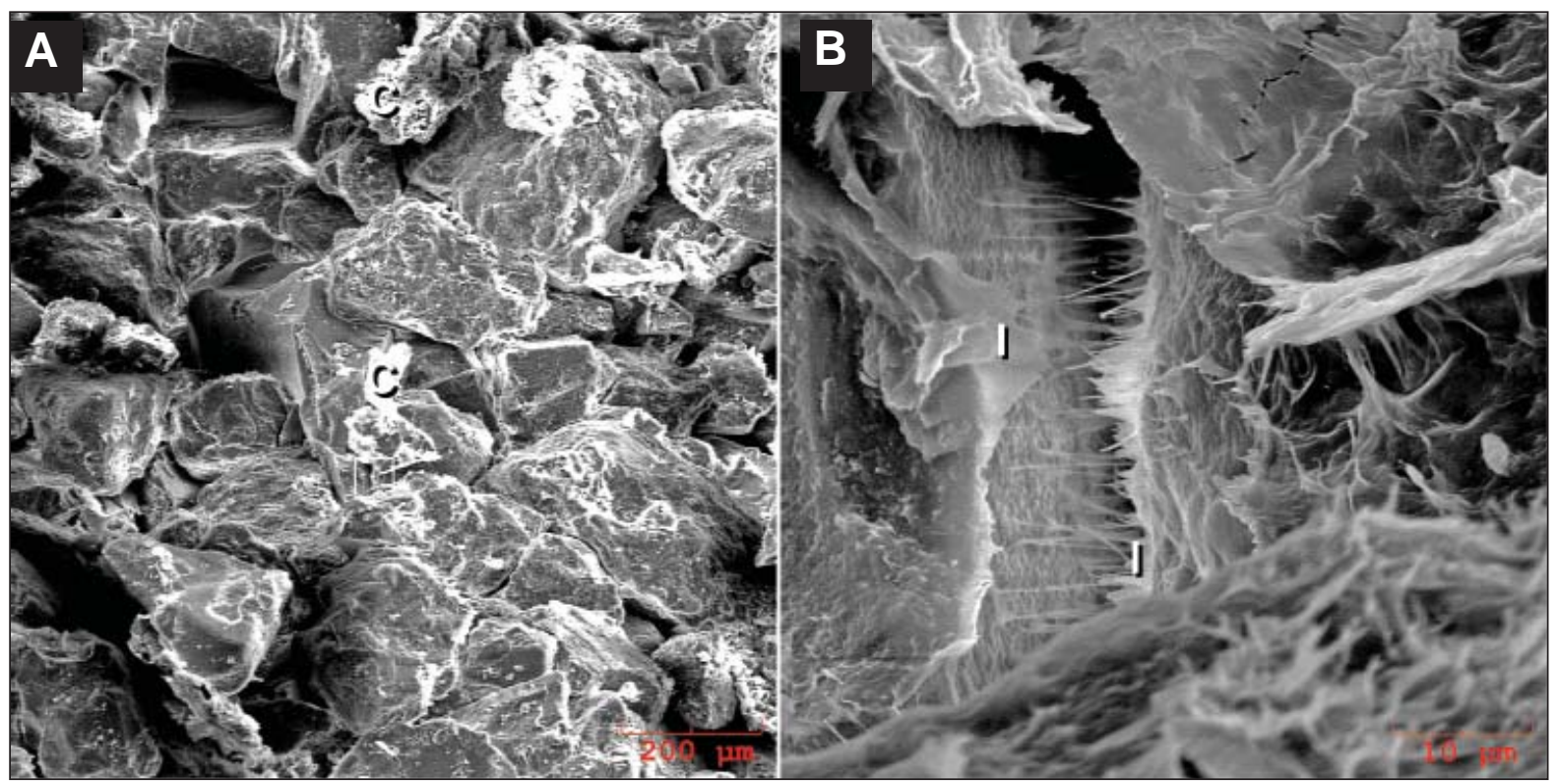

Figure 16. SEM photomicrograph of sandstone from the Stepovak Formation, ARCO North Aleutian COST \#1, 8,087.0'. A. General view showing angular nature of detrital grains. Bright patches are small areas of authigenic clay (C) coating grains. B. Enlarged view of outlined area showing fibrous authigenic clay, probably illite (I), lining small intergranular pore. 


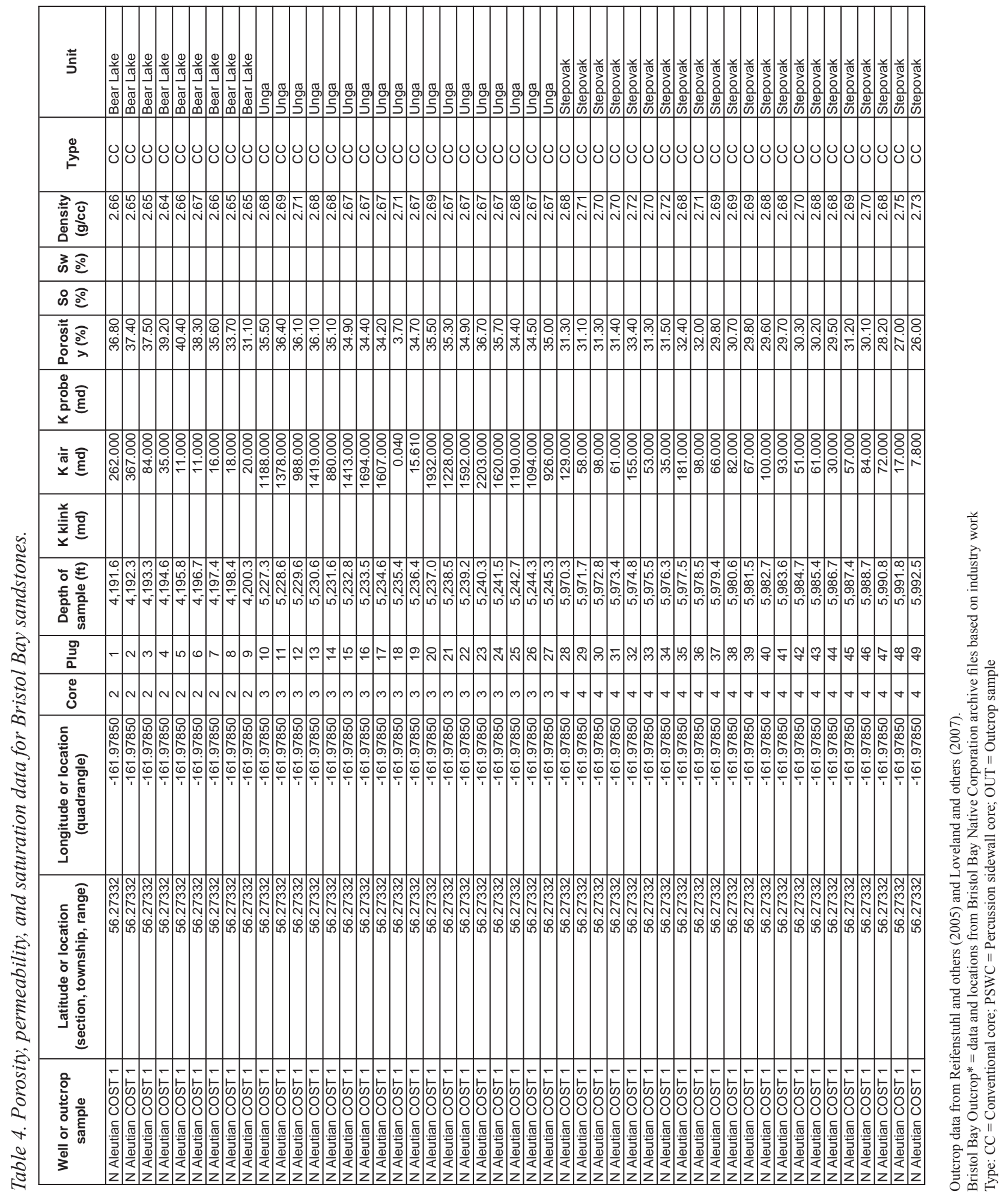




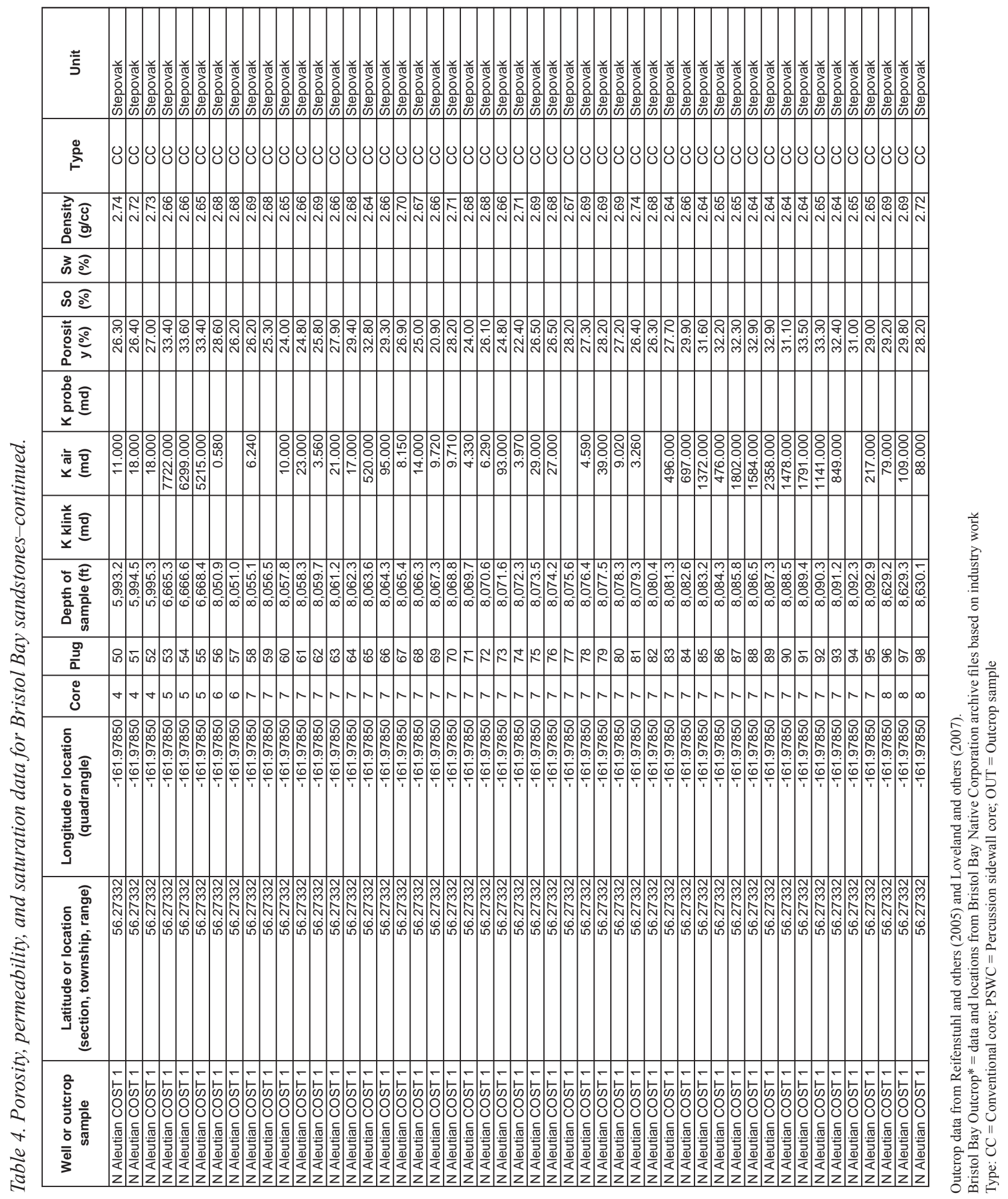




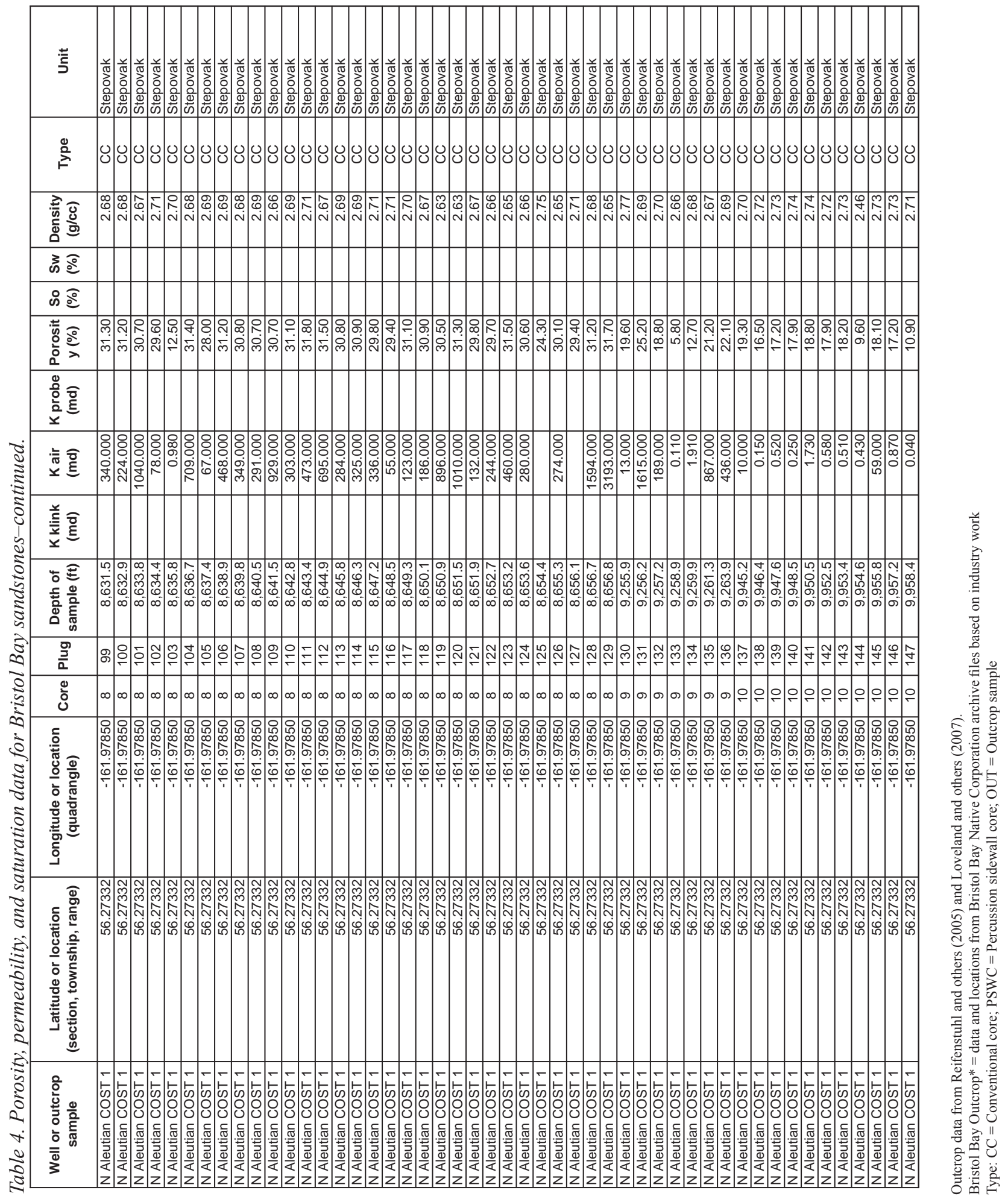




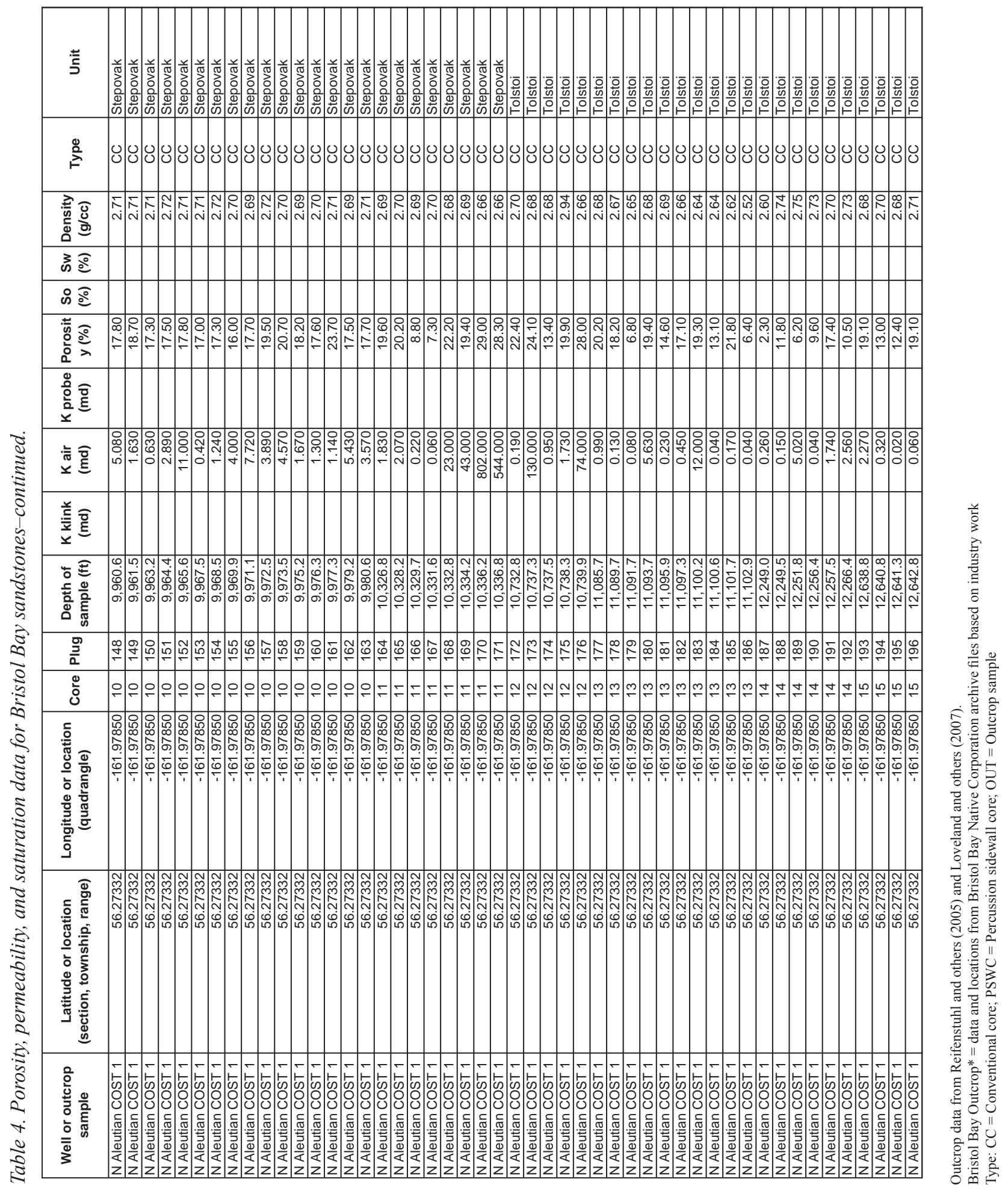




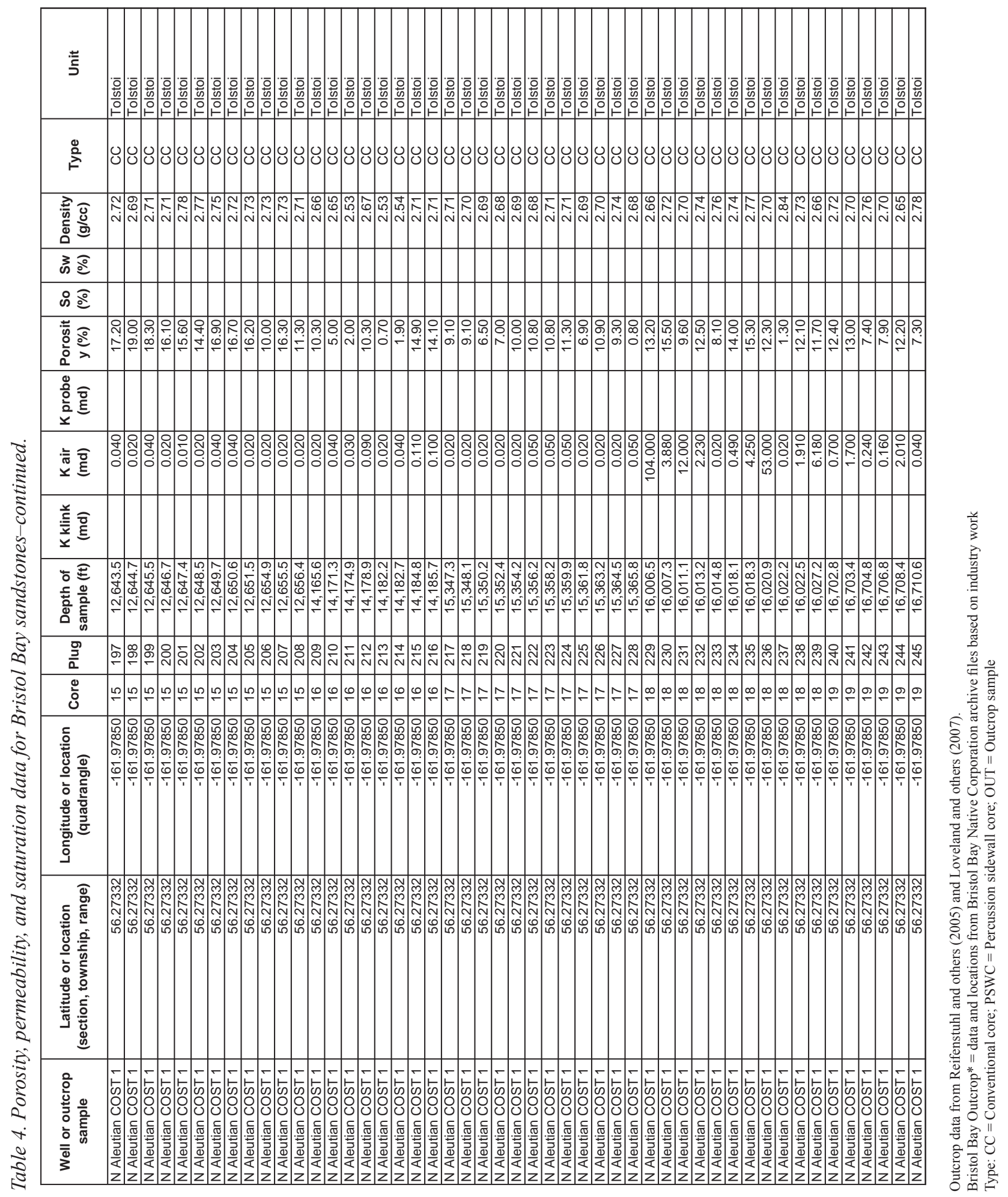




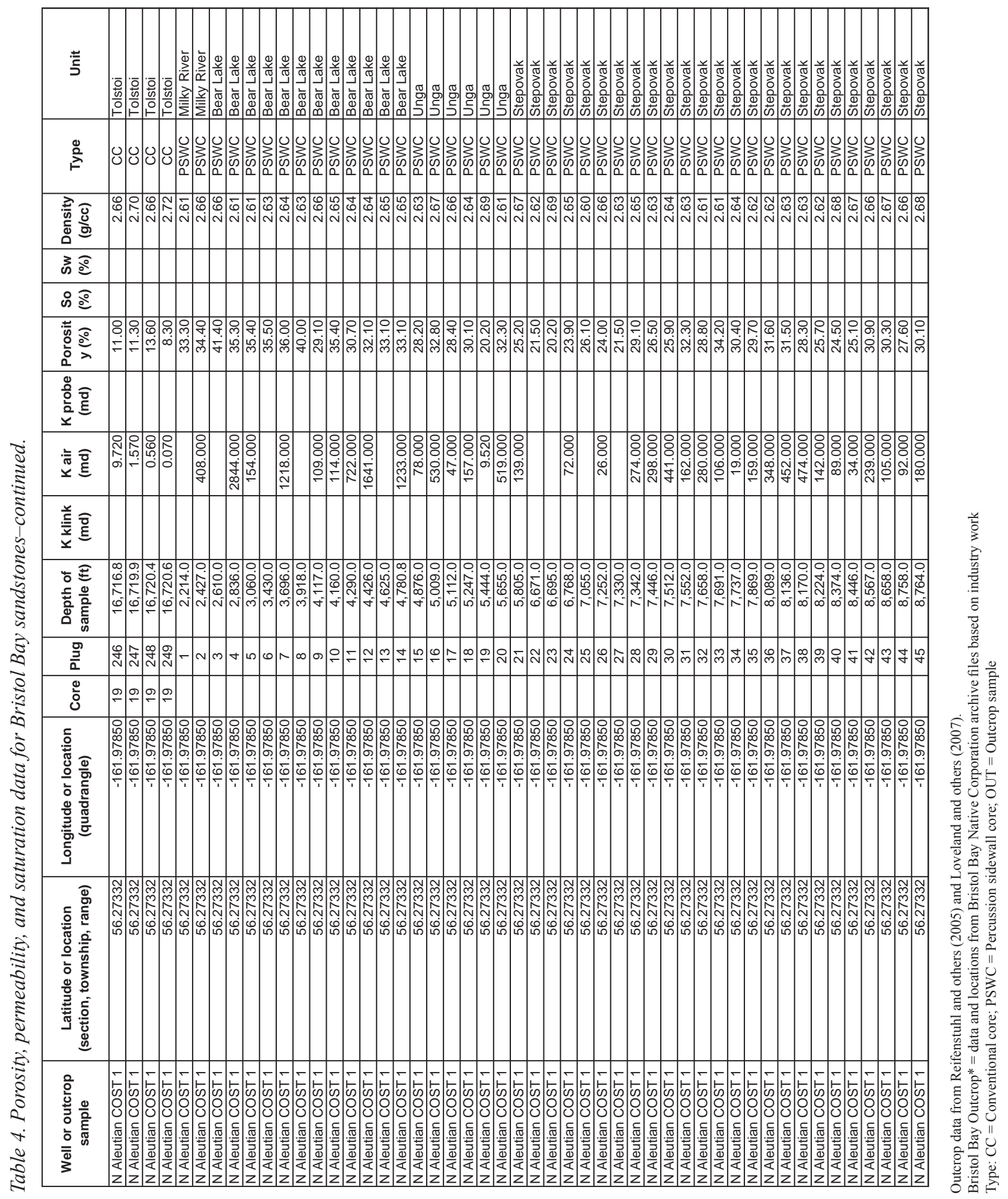




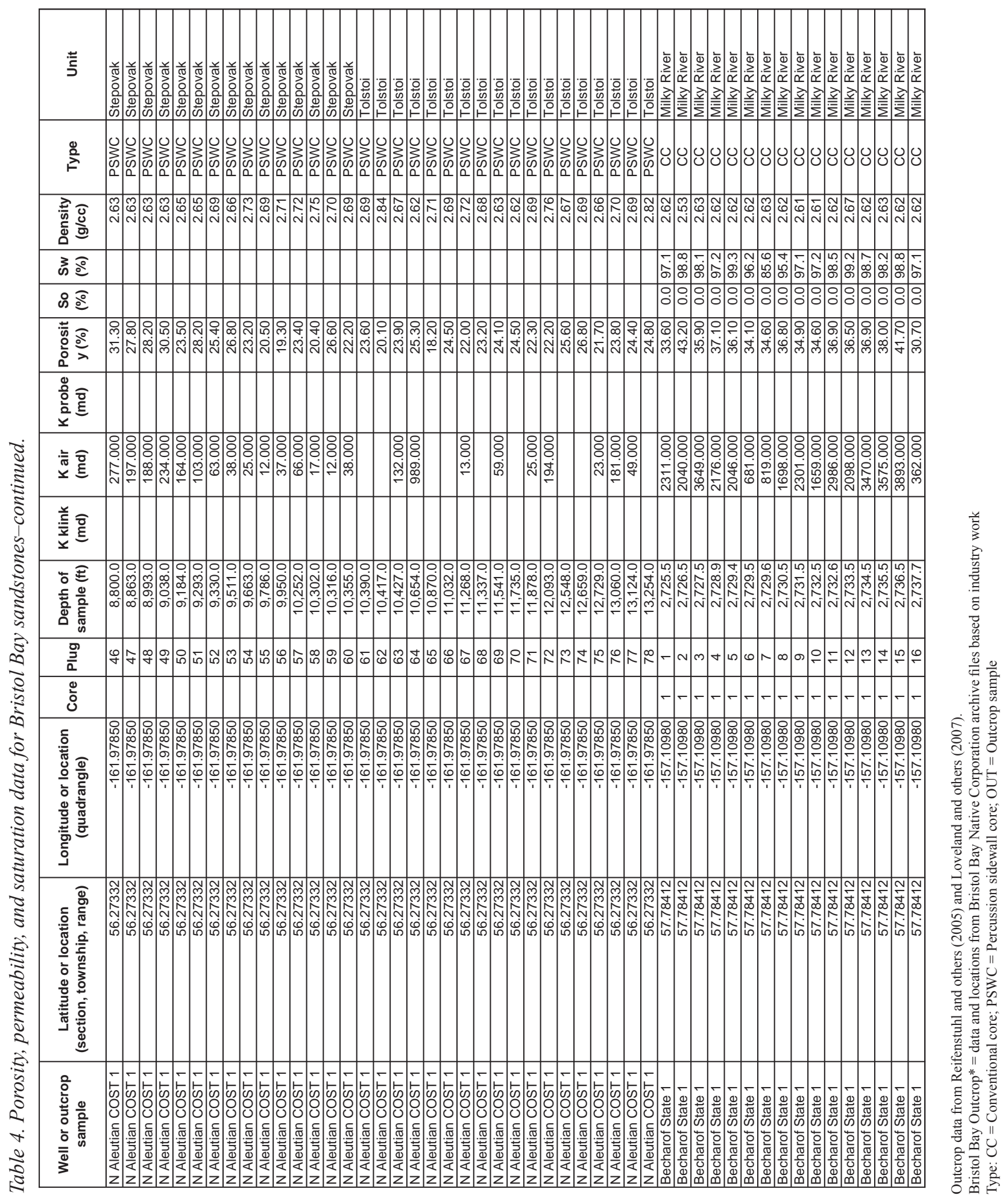




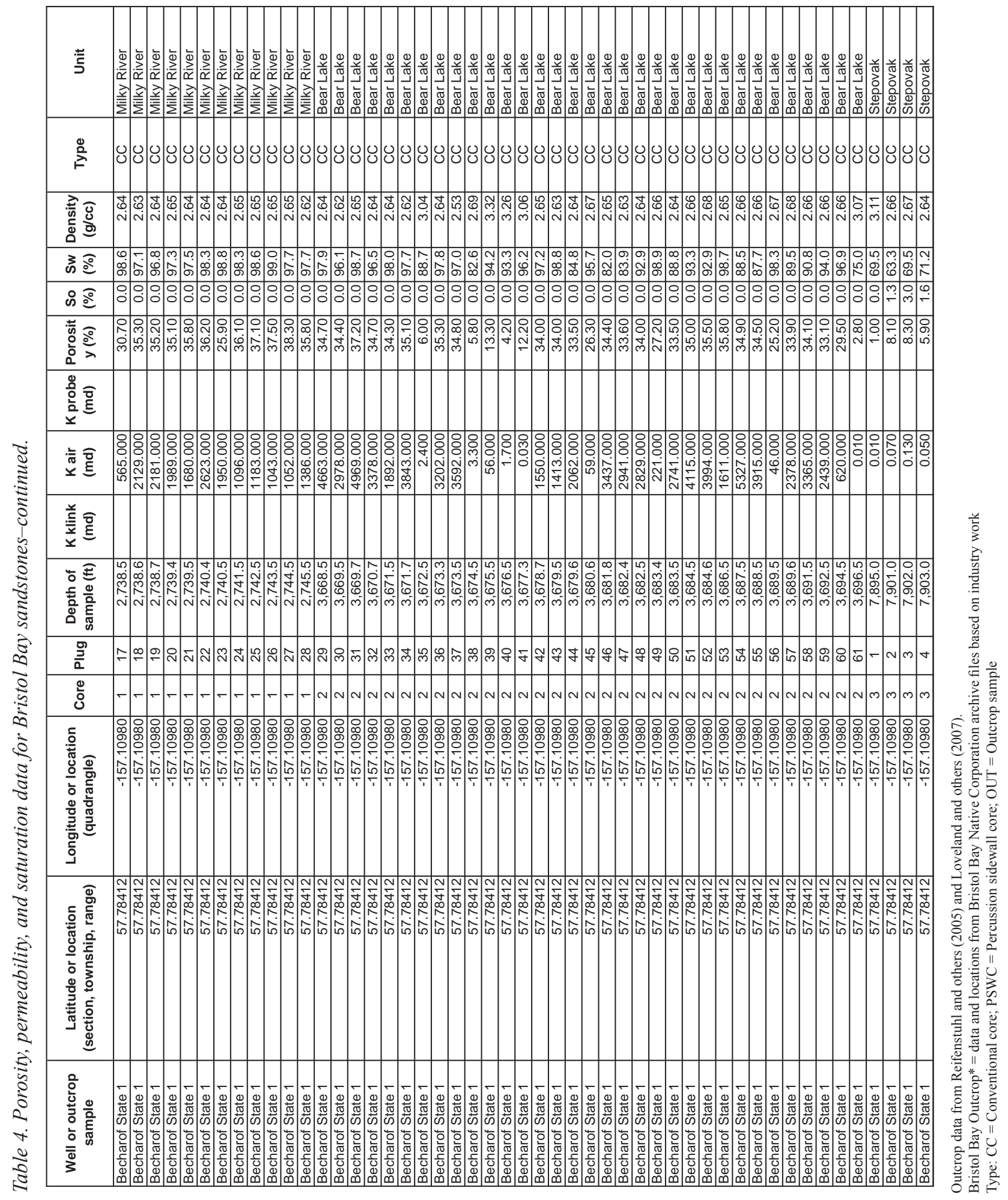




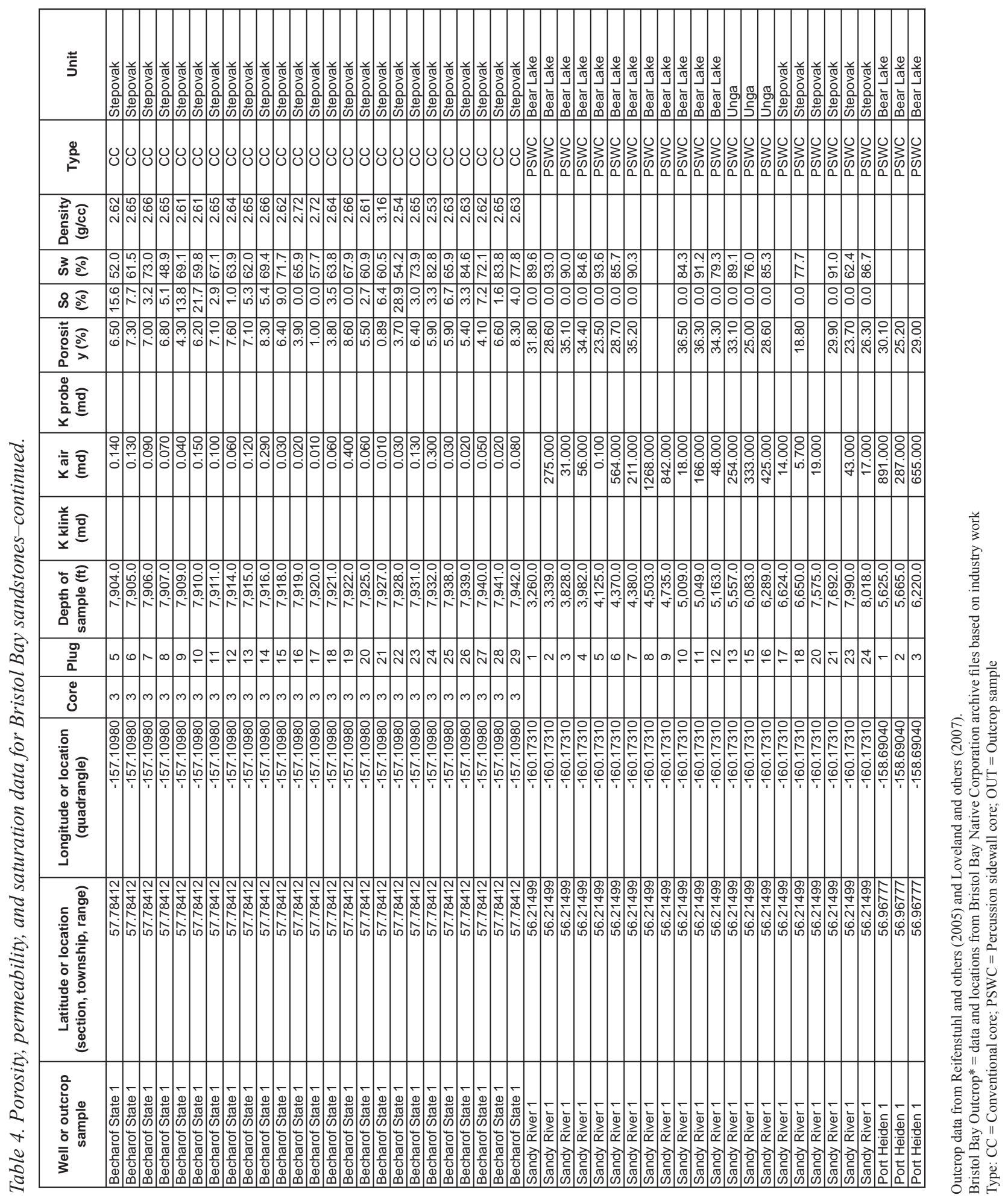




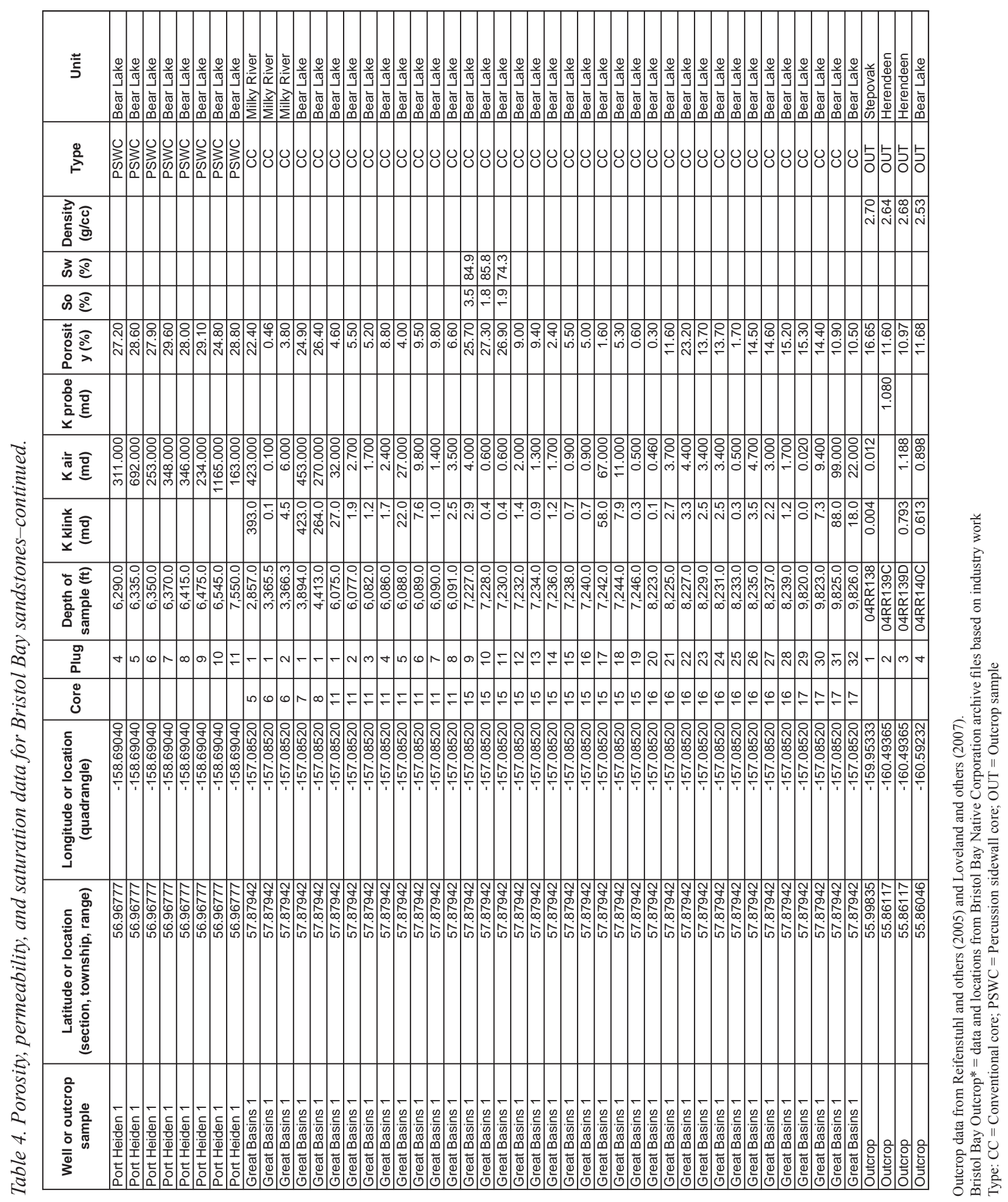




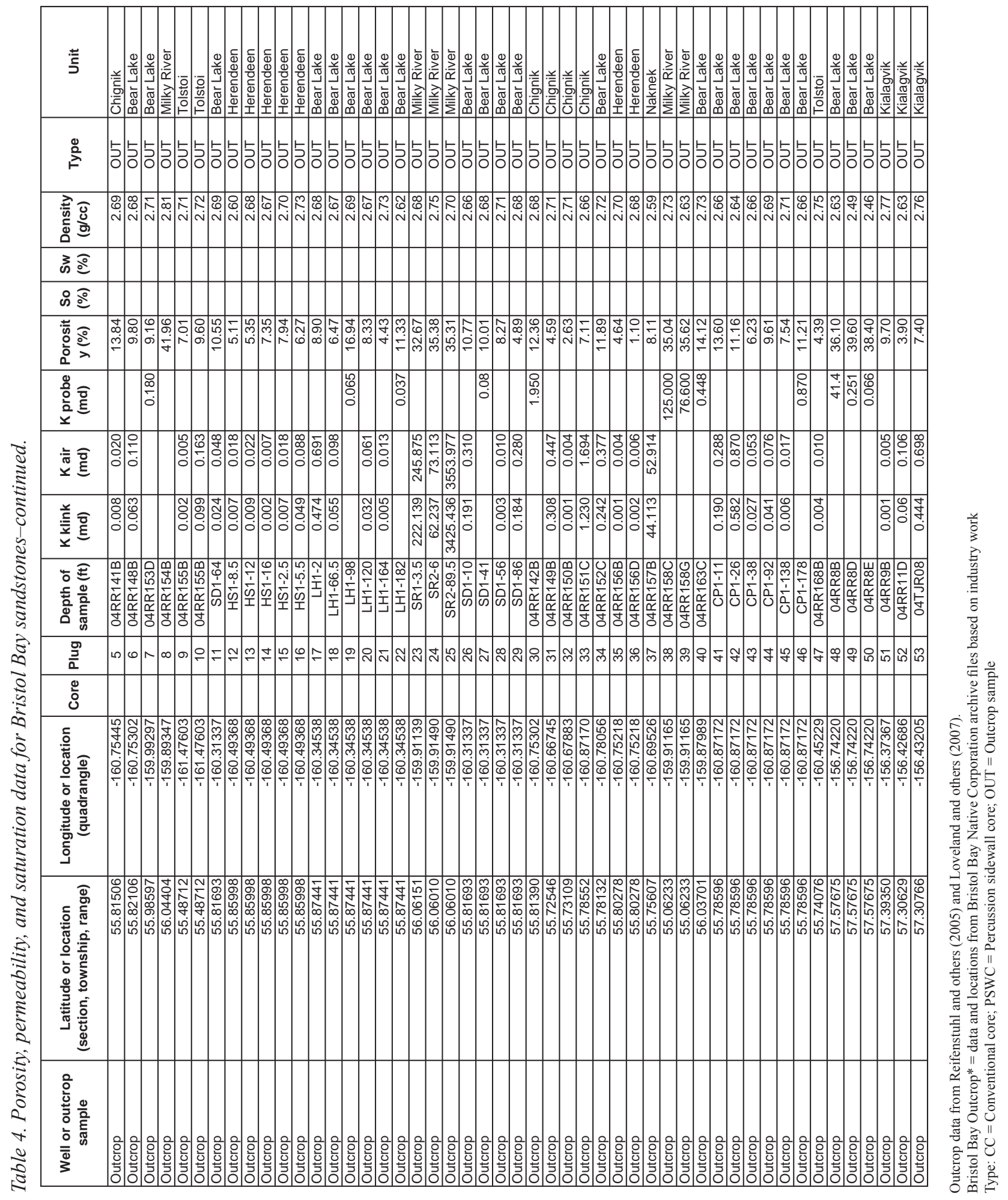




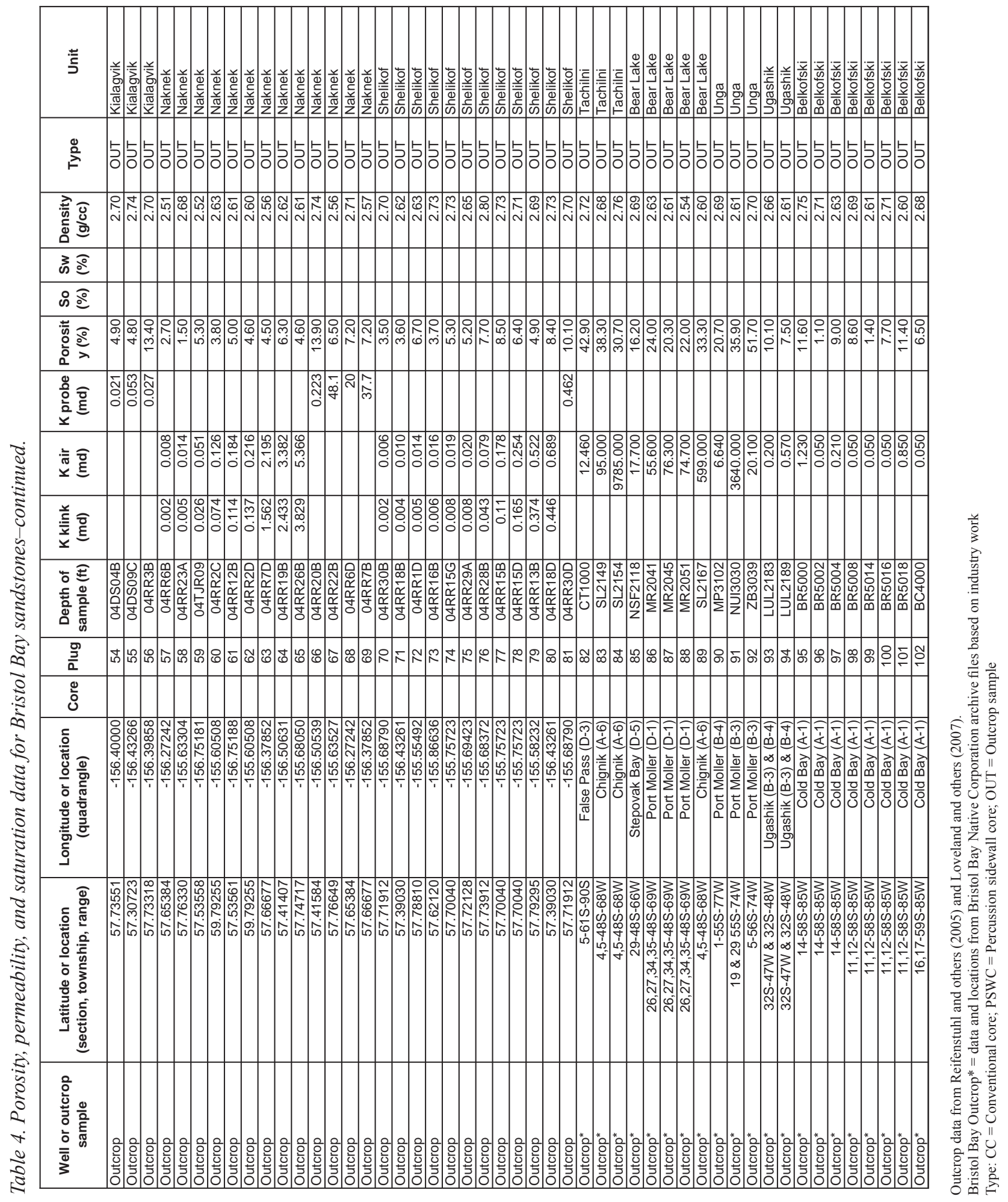




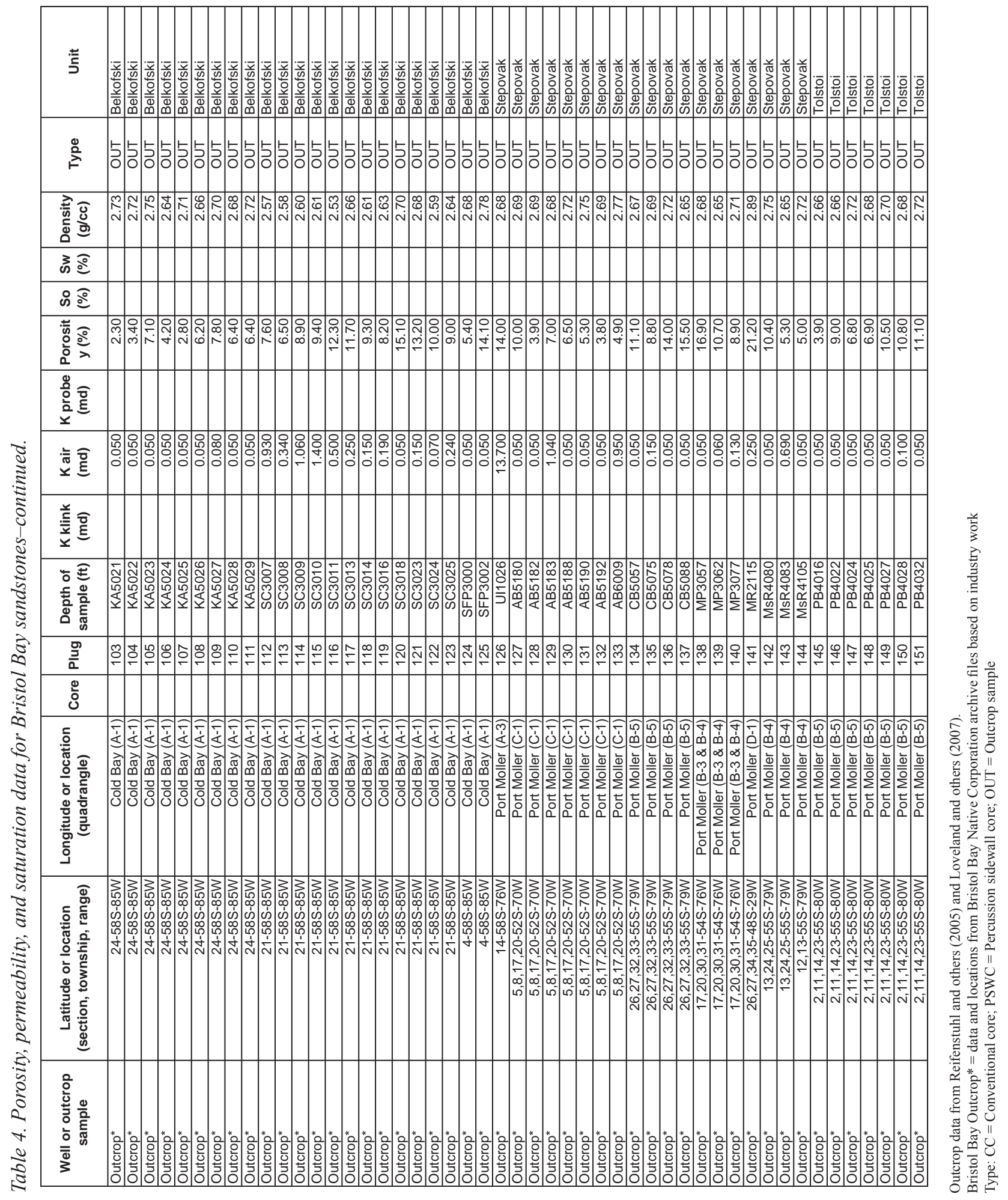




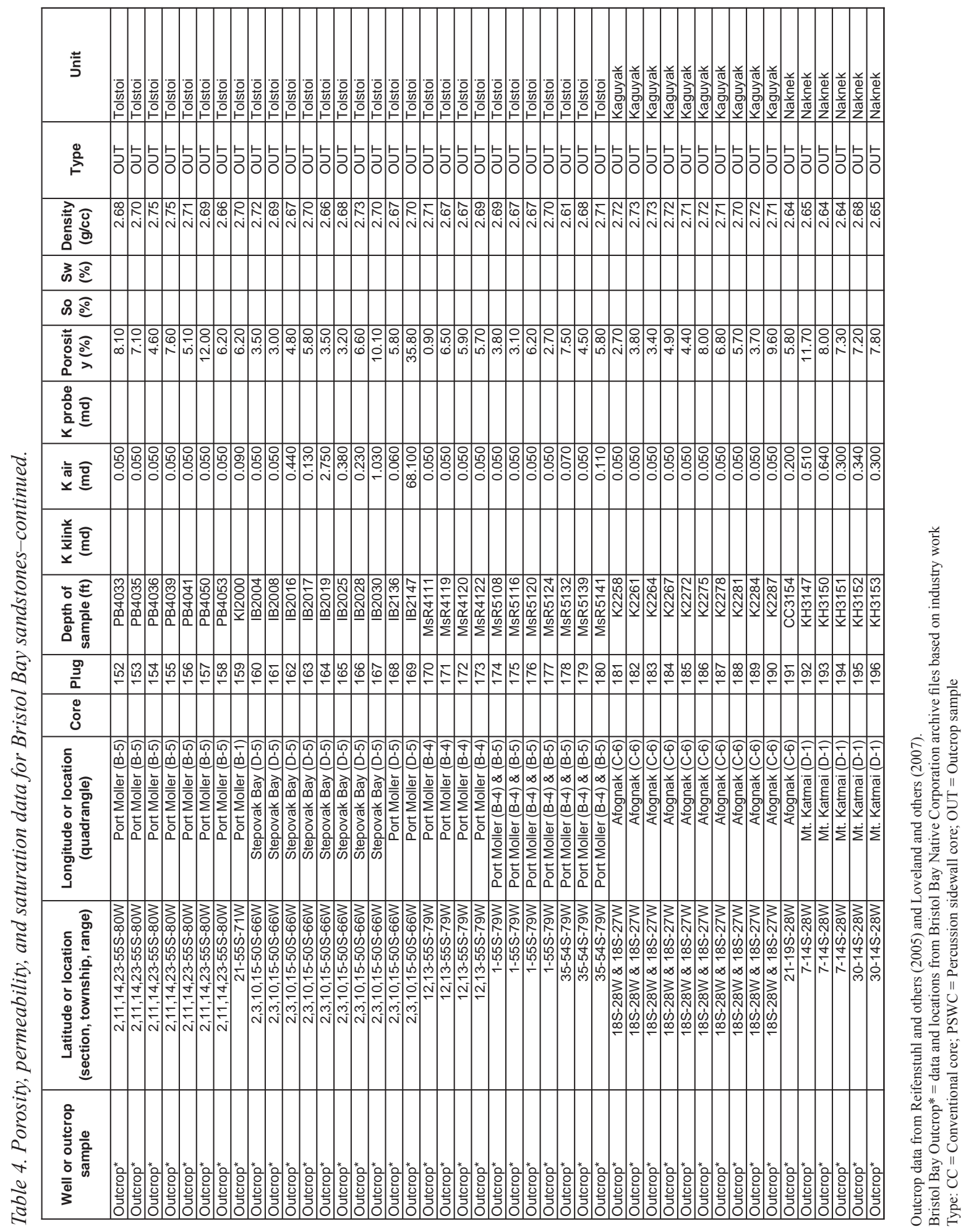




\section{REFERENCES CITED}

Burk, C.A., 1965, Geology of the Alaska Peninsula-Island Arc and Continental Margin: The Geological Society of America Memoir 99, 250 p., 3 sheets.

Decker, P.L., Finzel, E.S., Ridgway, K.D., Reifenstuhl, R.R., and Blodgett, R.B., 2005, Preliminary summary of the 2005 field season; Port Moller, Herendeen Bay, and Dillingham areas, Bristol Bay Basin, Alaska Peninsula: Alaska Division of Geological \& Geophysical Surveys Preliminary Interpretive Report 2005-7, 55 p., 2 sheets.

Detterman, R.L., Case, J.E., Miller, J.W., Wilson, F.H., and Yount, M.E., 1996, Stratigraphic framework of the Alaska Peninsula: U.S. Geological Survey Bulletin 1969-A, $74 \mathrm{p}$.

Dickinson, W.R., 1970, Interpreting detrital modes of graywacke and arkose, Journal of Sedimentary Petrology, v. 40, p. 695-707.

Dickinson, W.R. and Suczek, C.A., 1979, Plate tectonics and sandstone compositions: American Association of Petroleum Geologists, v. 63, p. 2,164-2,182.

Dickson, J.A.D., 1965, A modified staining technique for carbonates in thin section: Nature, v. 205, p.587.

Dickson, J.A.D., 1966, Carbonate identification and genesis as revealed by staining: Journal of Sedimentary Petrology, v. 36, p. 491-505.

Finzel, E.S., Reifenstuhl, R.R., Decker, P.L., and Ridgway, K.D., 2005, Sedimentology, stratigraphy, and hydrocarbon reservoir-source rock potential, using surface and subsurface data, of Tertiary and Mesozoic strata, Bristol Bay Basin and Alaska Peninsula: Alaska Division of Geological \& Geophysical Surveys Preliminary Interpretive Report 2005-4, 67 p.
Laniz, R.V., Stevens, R.E., and Norman, M.B., 1964, Staining of plagioclase feldspar and other minerals: U.S. Geological Survey Professional Paper 501-B, p. B152-B153.

Lindholm, R.C., and Finkelman, R.B., 1972, Calcite staining; Semiquantitative determination of ferrous iron: Journal of Sedimentary Petrology, v. 42, p. 239-242.

Loveland, A.M., Reifenstuhl, R.R., Gillis, R.J., and Decker, P.L., 2007, Outcrop sample results from mercury injection capillary pressure analyses, Bristol Bay, Alaska Peninsula: Alaska Division of Geological \& Geophysical Surveys Raw Data File 2007-3, 11 p.

Moore, D.M., and Reynolds, R.C., Jr., 1989, X-ray diffraction and the identification and analysis of clay minerals: Oxford University Press, 332 p.

Reifenstuhl, R.R., Bailey, R.D., and Finzel, E.S., 2005, Bristol Bay and Alaska Peninsula 2004; Fieldwork and sample analyses compilation report: Alaska Division of Geological \& Geophysical Surveys Preliminary Interpretive Report 2005-1, 20 p.

Strauch, A.L., Gillis, R.J., Reifenstuhl, R.R., and Decker, P.L., 2006, 2006 Bristol Bay, Alaska Peninsula field summary and outcrop sample results from porosity \& permeability and mercury injection capillary pressure analyses: Alaska Division of Geological \& Geophysical Surveys Raw Data File 2006-1, 65 p. 